\title{
Measuring Long Run Risks for Brazil`
}

\author{
DiEGO BRANDÃO* \\ CAio Almeida*
}

\begin{abstract}
We study the temporal structure of risk prices, risk exposures and expected market returns for Brazil assuming the economy follows a long run risks model. The model consists on an endowment economy where aggregate consumption and dividend growth contain predictable components, and a representative agent has Epstein-Zin recursive preferences with CES specification. We show that aggregate consumption in Brazil is sufficiently predictable to generate risk premia associated with Epstein-Zin preferences in excess of traditional compensations induced by power utility. Moreover, risk compensation is dominated by permanent shocks both in the short and long run, as Epstein-Zin preferences mitigate the price of temporary shocks' risk.
\end{abstract}

Keywords: Stochastic discount factor, long run risks, structural VAR, recursive utility JEL Codes: C1, E1, G1

\section{Introduction}

Consumption based models are the leading theoretical framework to explain the price of financial assets through their exposure to fundamental macroeconomic risks. Early empirical applications, however, found that standard consumptionbased models such as the CCAPM struggle to explain key features of financial data in the US (see e.g. Mehra \& Prescott, 1985 and Hansen \& Singleton, 1982). The long run risks model of Bansal and Yaron (2004) emerged as a successful consumption-based rationalization of the equity premium in the US through a combination of Epstein and Zin (1989) preferences and predictable consumption dynamics. These ingredients generate an intricate risk price structure that induces higher risk premia for assets exposed to uncertainty

Submitted on 27 September 2018; Reviewed on 28 November 2018

$\star$ This study was partially financed by the Coordenacao de Aperfeicoamento de Pessoal de Nivel Superior - Brasil (CAPES) - Finance Code 001. Caio Almeida gratefully acknowledges financial support from CNPq.

*Fundação Getulio Vargas, Escola Brasileira de Economia e Financas (FGV/EPGE), Rio de Janeiro, Brasil.

चdigusmao@hotmail.com حcalmeida@fgv.br 
affecting consumption in the long run, a key source of variation in the stochastic discount factor. Brazilian data, on the other hand, suggests mixed results with respect to the ability of standard consumption models to explain the equity premium (see Cysne, 2006 and Bonomo, 2004). Nonetheless, when post inflation Brazilian data is used in empirical applications, a power utility induced stochastic discount factor is incapable of generating enough variation to justify equity premium levels (see Cysne, 2006). ${ }^{1}$ For this reason, more elaborate versions of the standard model might be necessary to amplify the risk premium induced by Brazilian consumption dynamics.

In this paper, we investigate the asset pricing implications of a long run risks model in Brazil. More specifically, we explore specific channels in which the dynamic properties of Brazilian consumption affects the determination of a temporal structure of risk premia in an approximate long run risks model, where consumption potentially contains a predictable component, but volatilities are conditionally constant. Our main contribution is to show that aggregate consumption in Brazil is sufficiently predictable to generate risk premia associated with Epstein-Zin preferences, in excess to the traditional compensations induced by power utility. For moderate levels of risk aversion, about a third of short run risk premia is generated through the expansion of the standard model to incorporate long run risks components. In other words, if we had to answer the question: Based on consumption Brazilian data, does consumption dynamics induce a long run risk premium? The answer is yes, a sizeable premium.

A former literature on consumption-based models in Brazil, such as Issler and Piqueira (2000), Bonomo and Domingues (2002) and Sampaio (2002), identifies that the equity premium can be explained by conventional asset pricing models (such as the CCAPM), using acceptable levels of risk aversion. Those results are directly driven by the high volatility of aggregate consumption found in older datasets. Such exaggerated volatility might have been induced, most probably, by measurement errors in periods of high inflation and/or by untreated seasonal effects coming from quarterly data. Evidence on this direction is found by Soriano (2002) who uses quarterly consumption data treated for seasonality and identifies that the CCAPM cannot adequately replicate the Brazilian equity premium with reasonable risk-aversion coefficients. In Cysne (2006), where most observations correspond to the post hyperinflation period in Brazil, the

\footnotetext{
${ }^{1}$ Here we emphasize that since the standard deviation of the IBOVESPA returns (which represent the stock market index) is extremely high, equity premium levels end up highly dependent on the window of IBOVESPA returns analyzed, ranging from $1 \%$ to $50 \%$. Such variability itself justifies the adoption of models more general than the CCAPM.
} 
standard model is also unable to justify the equity premium. In our dataset, consisting of quarterly post hyperinflation data with seasonal effects adjustments, we show that the stochastic discount factor induced by power utility alone is able to generate moderate equity premia. Nonetheless, and most importantly, we also show that the introduction of a channel for long run risks makes the macro-finance model much more powerful and prepared to capture the large confidence band of "window-dependent" equity premium levels that exists in Brazil, even when only post hyperinflation data is used.

The long run risks model used in this paper consists on an endowment economy where aggregate consumption and dividend growth contain predictable components, summarized by a state variable. A representative agent has EpsteinZin recursive preferences with CES specifications. Conditional volatility of consumption growth is constant in time, contrasting with more traditional long run risks models, as Bansal and Yaron (2004), Colacito and Croce (2011) and Bansal and Shaliastovich (2012). Following Hansen, Heaton, Lee, and Roussanov (2007) and Hansen, Heaton, and Li (2008), the simplified constant volatility specification enables the approximation of the stochastic discount factor around a log-linear solution, obtained when the intertemporal elasticity of substitution is equal to one. The approximate solution is a linear-quadratic function of the state and can be recovered using preference parameters and a log-linear consumption growth dynamics.

Consumption predictability is a major ingredient in long run risks models. When consumption growth is i.i.d., we cannot distinguish the asset pricing implications originated from representative agents equipped with Epstein-Zin or power utility. We test if aggregate consumption in Brazil has a predictive component using past consumption and GDP growth as predictors. In our data, we find that these variables are able to predict one quarter ahead consumption growth with $R^{2}$ equal to $17 \%$. Consumption predictability in Brazil is not as strong as the one inferred from US datasets. Bansal, Kiku, and Yaron (2012) and Beeler and Campbell (2012) find that the VAR implied one year ahead consumption growth forecast in the US is summarized by a $R^{2}$ between 23 and $26 \%$, where consumption growth, price-dividend ratio and the risk free rate are used as endogenous variables. We did not find reliable data for Brazilian aggregate price-dividend ratios, so they were not included as predictors in our estimations. We did, however, include the risk free rate in multivariate predictive regressions, but the $R^{2}$ statistic's improvement was negligible.

We also test if cointegrating restrictions can be used to improve consumption 
predictability. If consumption and GDP are cointegrated, deviations from the cointegrating relation contains information about future outcomes. Bansal, Dittmar, and Kiku (2007), Bansal and Kiku (2011) and Da (2009) impose cointegration to improve dividend and return predictability. In Hansen et al. (2008), a cointegrating relation between corporate earnings and consumption is shown to increase variation in the stochastic discount factor, raising the price of risk associated with them. We did not find strong evidence for cointegration between consumption and GDP in our dataset, even though we cannot reject its existence using an unrestricted Johansen (1991) test. Imposing cointegration does not improve short run consumption predictability despite improving prediction for longer horizons. Nevertheless, ultimately we do not find cointegrating relations suitable to represent consumption dynamics and dismiss them to prevent misspecification issues.

In the long run risks economy the temporal properties of uncertainty are relevant for pricing. Epstein-Zin preferences under reasonable parameterizations amplify the compensation for risks that encode persistent dynamics. Therefore, permanent shocks associated with responses to consumption that are not expected to vanish over time, earn a higher premium than temporary shocks.

We investigate the sources of macroeconomic risks by the identification of structural shocks in our VAR system. We identify permanent and temporary shocks by restricting the latter to have no effects to consumption in the long run, a strategy proposed by Blanchard and Quah (1989) and adopted in Hansen et al. (2008). Our estimation results indicate that consumption in Brazil is mainly exposed to permanent risks. The short run response of consumption to a permanent shock is about 3.5 times higher than the effect of a temporary shock. We also find that Epstein-Zin preferences suppress the pricing effects of temporary risks. This result implies that the risk compensation for payoffs exposed mainly to temporary shocks is small, a consequence of the risk price structure generated by the long run risks model. A qualitatively similar result was obtained by Hansen et al. (2008), whose findings using datasets from the US indicate that permanent shocks have twice the short run response of a temporary shock. This pattern can be explained by the fact that temporary shocks can only exist in this framework if consumption is predictable, otherwise, in case it is represented by the familiar random walk specification, all shocks affecting consumption would be permanent. As our data suggests, complementing the international evidence, consumption has a small but significant predictable component, which is reflected in the modest size of temporary shocks. 
The asset pricing implications of the model are simplified by the closed form structure of the stochastic discount factor. In particular, it is possible to characterize how the compensation for exposure to uncertainty evolves when we change the horizon of investment. The temporal properties of the interaction between macroeconomic risks and asset prices is the object of a growing literature, see e.g. Parker and Julliard (2005), Campbell and Vuolteenaho (2004) and Lettau and Wachter (2007). Part of this research investigates how the allocation of risk compensation through time affects one period risk premia and generates cross section variation not explained by the CCAPM. In this paper, a temporal structure for prices and exposures to risk is obtained by decomposing the innovations to the stochastic discount factor, as it highlights the sources of risk compensation in this long run risks economy. Our decomposition is focused on risk prices and how Epstein-Zin preferences affect the exposure of the stochastic discount factor to uncertainty.

The estimated model suggests that risk prices in Brazil, for the particular window of time analyzed, are mainly driven by power utility induced variations originated by innovations to consumption growth, although the Epstein-Zin term also contains significant risk prices. The role of Epstein-Zin preferences to the determination of risk prices, which is associated with changes in expected long run levels of consumption, depends on dynamic effects of the underlying shock. We find that the price of temporary risks to consumption is close to zero because, although a positive temporary shock increases discounting through the usual power utility component, it represents bad news for consumption growth, as it must be reversed in the future, mitigating the risk price effect through the Epstein-Zin term. Estimated permanent risk prices, on the other hand, are reinforced by Epstein-Zin preferences, as the short and long run effect on aggregate consumption have the same direction.

Long run risk prices, when the horizon of investment approaches infinity, are enhanced by the predictability characteristics of Brazilian consumption, where overall uncertainty is accumulated over time, instead of fading out. This result diverges from the one found in Van Binsbergen, Brandt, and Koijen (2012) using US data, where payoffs realized in the short run receive a higher risk premium when compared to payoffs paid in longer horizons.

The results for risk premia mirror the risk price structure of the stochastic discount factor. Dividends paid one period ahead are compensated mainly for concerns about next period consumption and cash flow growth variability. EpsteinZin induced premium, however, represents about a third of expected excess 
one period return, increasing its contribution when the risk aversion coefficient is high. For longer investment horizons, the risk premium also increases as a consequence of accumulated uncertainty caused by the estimated consumption predictability. Our results indicate that, although aggregate consumption and persistence patterns are relatively weak in Brazil, they are still able to generate significant compensation for non diversifiable risks through the Epstein-Zin channel.

The rest of of the paper is organized as follows. Section 2 describes the adopted model. It first introduces the state space representation for the random vector that drives all the uncertainty in the economy, including consumption, dividends and the pricing kernel. Next, it presents the agent's preferences and optimization problem, the implied Stochastic Discount Factor and its pricing implications for the term structure of dividends. Section 3 presents model estimation starting with an analysis of the statistical properties of the consumption process including stationarity and cointegration tests with the GDP process. It also identifies consumption dynamics via a VAR model with transitory and permanent shocks that characterize the long run risks model. Section 4 details asset pricing implications coming from predictability patterns of the Brazilian consumption time series. Section 5 provides concluding remarks.

\section{The Model}

The economy follows a long run risks model where shocks are restricted to have deterministic volatility. The two main components of the model are a representative agent with Epstein-Zin preferences and a predictable consumption process that generates interactions between the stochastic discount factor and the conditional expectation of future dividend payments.

The economy is modeled in a log-linear framework, so we are able to approximate a solution in closed form and assess more clearly the asset pricing implications for Brazilian data. An exact closed form solution is obtained in the special case where the intertemporal elasticity of substitution (IES) is equal to one, so utility can be written as a log-linear function of the state variable. When the elasticity is different from one, we approximate the value function around the log-linear solution and obtain a quadratic function of the state.

Asset prices are obtained using a pricing operator generated by the stochastic discount factor. The time $t$ value of a dividend paid $j$ periods ahead can be computed by repeated iteration of the pricing operator. We are also able to use this operator to price assets paying dividends in different maturities and recover 
a temporal structure for expected returns. We are specially interested in the expected return of assets paying dividends one period ahead or in the distant future, where a limiting solution can be obtained.

\section{$2.1 \quad$ Endowments}

Predictability is summarized by the state variable $x_{t}$, a $k$-dimensional vector satisfying

$$
x_{t+1}=G x_{t}+H \varepsilon_{t+1},
$$

where $\left\{\varepsilon_{t+1}\right\}$ is a $k$-dimensional sequence of normally distributed i.i.d. vectors of shocks with zero mean and covariance $I$. We assume that all eigenvalues of $G$ lie inside the unit circle to guarantee stationarity of $x_{t}$. Any vector autoregression (VAR) with $p$ lags can be written as a VAR(1) by appropriately redefining variables, so the number of lags in the state variable representation (1) is adopted without loss of generality.

The logarithm of consumption growth $\Delta c_{t+1}$ satisfies

$$
\Delta c_{t+1}=\mu_{c}+U_{c} x_{t}+\lambda_{c} \varepsilon_{t+1},
$$

where $\mu_{c}$ is the unconditional mean of consumption growth, $\lambda_{c}$ is a $1 \times k$ vector controlling short term exposure to uncertainty, and $U_{c}$ is a $1 \times k$ vector that governs predictability patterns. The state variable shifts the conditional expectation for next period consumption by $U_{c} x_{t}$ and, because of its persistent structure controlled by $G$, also alters the expectations of future consumption levels.

The short term dynamic specification of consumption growth in equation (2) encodes long run properties of consumption levels. One way to extract these properties is using the Beveridge and Nelson (1981) decomposition to write:

$$
c_{t}=\mu_{c} t+U_{c}^{*} x_{t}+\pi_{c} z_{t},
$$

where

$$
\begin{aligned}
U_{c}^{*} & =-U_{c}(I-G)^{-1}, \\
\pi_{c} & =\lambda_{c}+U_{c}(I-G)^{-1} H, \\
z_{t} & =\sum_{j=1}^{t} \varepsilon_{j} .
\end{aligned}
$$

Consumption levels are decomposed as the sum of a deterministic trend $\mu_{c} t$, 
a stationary process $U_{c}^{*} x_{t}$ and a martingale $\pi_{c} z_{t}$. Initial conditions for $c_{t}$ and $x_{t}$ have no implications for our results, so we set them to zero for simplicity. Writing consumption as (3) emphasizes its permanent components, which, as will become clear later, are the only relevant information to price assets whose dividends maturity approaches infinity.

If $U_{c}=0$, so consumption growth is i.i.d, there are no temporary components in the level of consumption and all shocks have permanent effects. When consumption is predictable, part of the effects of shocks is captured by the stationary component $U_{c}^{*} x_{t}$ and the remaining effect is captured by the martingale term. The effect of a shock to the martingale in consumption can be written as the cumulated responses to consumption growth:

$$
\pi_{c}=\lambda_{c}+U_{c}\left(\sum_{j=0}^{\infty} G^{j}\right) H .
$$

To understand what this expression represents, notice that, by construction, the martingale $\pi_{c} z_{t}$ is the asymptotic consumption level's conditional expectation when the deterministic trend is already taken into account:

$$
\begin{aligned}
\lim _{j \rightarrow \infty} \mathbb{E}_{t}\left[c_{t+j}-\mu_{c}(t+j)\right] & =c_{t}+\lim _{j \rightarrow \infty} \mathbb{E}_{t}\left[\sum_{i=1}^{t+j}\left(\Delta c_{i}-\mu_{c}\right)\right] \\
& =c_{t}+\left(\lambda_{c}+U_{c}(I-G)^{-1} H\right) \sum_{i=1}^{t} \varepsilon_{i} \\
& =c_{t}+\pi_{c} z_{t}
\end{aligned}
$$

The above relation suggests that we can interpret $\pi_{c} z_{t}$ as a stochastic trend for consumption: shocks to the martingale process represent new information with respect to long run levels of consumption. On the other hand, shocks to the stationary term are expected to vanish through time and have no impact on consumption asymptotically.

The same dynamic specification is used for dividend growth $\Delta d_{t+1}$ :

$$
\Delta d_{t+1}=\mu_{d}+U_{d} x_{t}+\lambda_{d} \varepsilon_{t+1}
$$

The structure above add flexibility to model market dividend streams, allowing trends, predictability patterns and responses to uncertainty to be different from the consumption process. A Beveridge and Nelson decomposition 
analogous to equation (3) holds:

$$
d_{t}=\mu_{d} t+U_{d}^{*} x_{t}+\pi_{d} z_{t}
$$

where

$$
\begin{aligned}
U_{d}^{*} & =-U_{d}(I-G)^{-1}, \\
\pi_{d} & =\lambda_{d}+U_{d}(I-G)^{-1} H .
\end{aligned}
$$

\section{$2.2 \quad$ Preferences}

Preferences are summarized by a representative agent with Epstein and Zin (1989) utility $V_{t}$ that satisfies the constant elasticity of substitution (CES) recursion:

$$
V_{t}=\left[(1-\beta) C_{t}^{1-\rho}+\beta \mathcal{R}_{t}\left(V_{t+1}\right)^{1-\rho}\right]^{\frac{1}{1-\rho}}
$$

where $\beta$ is the subjective discount factor and $\rho$ is the reciprocal of the IES. The function $\mathcal{R}_{t}(\cdot)$ also has a CES functional form and operates a risk correction to the continuation value $V_{t+1}$ that generates a certainty equivalent of the next period utility:

$$
\mathcal{R}_{t}\left(V_{t+1}\right)=\mathbb{E}_{t}\left[V_{t+1}^{1-\gamma}\right]^{\frac{1}{1-\gamma}}
$$

where the parameter $\gamma$ controls the risk aversion of the representative agent.

The constant relative risk aversion (CRRA) family is the solution to the utility recursion (15) whenever $\rho=\gamma$. In these cases, the attitude of the representative agent with respect to dispersion of consumption through time and between states of nature are tied together. The generality of the Epstein-Zin preference class comes from the fact that the IES and risk aversion parameters can be chosen separately. In this case, it is possible to amplify risk premia using larger risk aversion coefficients without much impact on risk free rates.

A log-linear exact solution for the representative agent's utility is available when $\rho=1$. For different IES parameters, Hansen et al. (2007) and Hansen et al. (2008) obtain closed form approximate solutions around the log-linear case. To obtain these approximations, define

$$
v_{t}=\log \left(\frac{V_{t}}{C_{t}}\right)
$$


For any given $\rho, v_{t}$ must satisfy

$$
v_{t}=\frac{1}{1-\rho} \log \left((1-\beta)+\beta \mathcal{R}_{t}\left(\exp \left\{v_{t+1}+\Delta c_{t+1}\right\}\right)^{1-\rho}\right) .
$$

In the limiting case $\rho=1$, the above recursion can be written as

$$
v_{t}=\frac{\beta}{1-\gamma} \log \mathbb{E}_{t}\left[\exp \left\{(1-\gamma)\left(v_{t+1}+\Delta c_{t+1}\right)\right\}\right] .
$$

It can be verified that a solution for equation (19) is given by

$$
v_{t}=\mu_{v}+U_{v} x_{t}
$$

where

$$
\begin{aligned}
\mu_{v} & =\frac{\beta}{1-\beta} \mu_{c}+\frac{\beta}{1-\beta} \frac{(1-\gamma)}{2}\left|\lambda_{c}+\beta U_{c}(I-\beta G)^{-1} H\right|^{2} \\
U_{v} & =\beta U_{c}(I-\beta G)^{-1}
\end{aligned}
$$

The first term in $\mu_{v}$ is the sum, discounted by the subjective discount factor $\beta$, of the unconditional expectation of future consumption growth. The second component is a Jensen adjustment induced by $\mathcal{R}_{t}(\cdot)$ and the discounted cumulated responses of consumption growth to shocks. The vector $U_{v}$ summarizes the effect on utility of changes in the state variable and can be equivalently be written as $U_{v}=\beta U_{c} \sum_{j=0}^{\infty} \beta^{j} G^{j}$. The expected value of a future state $x_{t+j}$, conditional on information in $t$, is given by $\mathbb{E}_{t} x_{t+j}=G^{j} x_{t}$, so $U_{v} x_{t}$ captures the discounted sum of changes in future predictable consumption growth.

To emphasize the dependence of the utility process on the intertemporal elasticity of substitution, we write $v_{t}^{\rho}$ as the continuation value from now on. For any given $\rho$, the value function $v_{t}^{\rho}$ is approximated using perturbation methods by expanding it around the log-linear solution solution obtained for $\rho=1$ :

$$
v_{t}^{\rho} \approx v_{t}^{1}+(\rho-1) D v_{t}^{1}
$$

The stochastic process $D v_{t}^{1}$ is the derivative of $v_{t}^{\rho}$ with respect to $\rho$ and evaluated at $\rho=1$. This derivative can be obtained directly using equation (18) and the solution for $v_{t}^{1}$ given by (20). It can be shown that $D v_{t}^{1}$ satisfy the recursive relation:

$$
D v_{t}^{1}=-\frac{(1-\beta)}{2 \beta}\left(v_{t}^{1}\right)^{2}+\beta \mathbb{E}_{t}^{*}\left[D v_{t+1}^{1}\right]
$$


where the conditional expectation operator $\mathbb{E}_{t}^{*}[\cdot]$ is obtained using a probability measure distorted by the Radon-Nikodym variable:

$$
\frac{\exp \left\{(1-\gamma)\left(v_{t+1}^{1}+\Delta c_{t+1}\right)\right\}}{\mathbb{E}_{t}\left[\exp \left\{(1-\gamma)\left(v_{t+1}^{1}+\Delta c_{t+1}\right)\right\}\right]}
$$

The solution to equation (24) satisfy

$$
D v_{t}^{1}=-\frac{(1-\beta)}{2 \beta} \sum_{j=0}^{\infty} \beta^{j} \mathbb{E}_{t}^{*}\left[\left(v_{t+j}^{1}\right)^{2}\right]
$$

so the derivative $D v_{t}^{1}$ has a linear quadratic form on the state variable that is described in the Appendix.

\subsection{The Representative Agent's Problem}

Suppose the agent has access to an asset that pays the dividend stream $\left\{D_{t}\right\}_{j=0}^{\infty}$. We denote the wealth of the agent in period $t$ by $W_{t}$ and the one period gross return by $R_{t}$, so the budget constraint satisfy the recursion

$$
W_{t+1}=\left(W_{t}-C_{t}\right) R_{t+1}
$$

The representative agent's problem is given by

$$
\begin{aligned}
V\left(W_{t}\right)=\max _{C_{t}} & {\left[(1-\beta) C_{t}^{1-\rho}+\beta \mathcal{R}_{t}\left(V\left(W_{t+1}\right)\right)^{1-\rho}\right]^{\frac{1}{1-\rho}} } \\
\text { s.t. } \quad & \mathcal{R}_{t}\left(V\left(W_{t+1}\right)\right)=\mathbb{E}_{t}\left[V_{t+1}^{1-\gamma}\right]^{\frac{1}{1-\gamma}}, \\
& W_{t+1}=\left(W_{t}-C_{t}\right) R_{t+1}, \\
& W_{t} \text { is given, }
\end{aligned}
$$

and the first order condition is

$$
\left[C_{t}\right]:(1-\beta) C_{t}^{-\rho}=\mathbb{E}_{t}\left[\beta\left(\frac{V\left(W_{t+1}\right)}{\mathcal{R}_{t}\left(V\left(W_{t+1}\right)\right)}\right)^{\rho-\gamma} \frac{V^{\prime}\left(W_{t+1}\right)}{V\left(W_{t+1}\right)^{\rho}} R_{t+1}\right]
$$

The solution for the agent's problem must also satisfy the Envelope condition, which after some rearrangements can be written as

$$
\frac{V^{\prime}\left(W_{t}\right)}{V\left(W_{t}\right)^{\rho}}=\mathbb{E}_{t}\left[\beta\left(\frac{V\left(W_{t+1}\right)}{\mathcal{R}_{t}\left(V\left(W_{t+1}\right)\right)}\right)^{\rho-\gamma} \frac{V^{\prime}\left(W_{t+1}\right)}{V\left(W_{t+1}\right)^{\rho}} R_{t+1}\right] .
$$


Using equations (29) and (30), we get

$$
\frac{V^{\prime}\left(w_{t}\right)}{V\left(w_{t}\right)^{\rho}}=(1-\beta) c_{t}^{-\rho}
$$

The Envelope condition (30), together with equation (31), generates the Euler equation for the representative agent's problem:

$$
\mathbb{E}_{t}\left[\beta\left(\frac{C_{t+1}}{C_{t}}\right)^{-\rho}\left(\frac{V\left(W_{t+1}\right)}{\mathcal{R}_{t}\left(V\left(W_{t+1}\right)\right)}\right)^{\rho-\gamma} R_{t+1}\right]=1
$$

\subsection{Stochastic Discount Factor}

The asset pricing implications of the model are determined by the properties of its stochastic discount factor $S_{t, t+1}$, the ratio between marginal utilities in periods $t+1$ and $t$. The covariance between the stochastic discount factor and asset payoffs determines risk premia in this economy, so we establish the sources of variation to $S_{t, t+1}$ and how they are related to future cash flows.

The stochastic discount factor is obtained directly from the Euler equation:

$$
S_{t, t+1}=\beta\left(\frac{C_{t+1}}{C_{t}}\right)^{-\rho}\left(\frac{V_{t+1}}{\mathcal{R}_{t}\left(V_{t+1}\right)}\right)^{\rho-\gamma} .
$$

Epstein-Zin preferences generate a stochastic discount factor that depends on the continuation value $V_{t+1}$, which is not observable. As we have seen, however, when $\rho=1$ we are able to express $v_{t}^{1}$ as a linear function of the state and, for any given $\rho$, we can write $v_{t}^{\rho}$ as a linear quadratic function of $x_{t}$ using the first order approximation in equation (23). As shown in Hansen et al. (2007), it is possible to obtain similar representations for the logarithm of the stochastic discount factor $s_{t, t+1}^{\rho}$, where again the superscript is used to emphasize dependence on the parameter $\rho$. In the special case $\rho=1$, we can write $s_{t, t+1}^{1}$ as

$$
\begin{aligned}
s_{t, t+1}^{1}=\log \beta- & \Delta c_{t+1} \\
& +(1-\gamma)\left(v_{t+1}^{1}+\Delta c_{t+1}-\log \mathcal{R}_{t}\left(\exp \left\{v_{t+1}^{1}+\Delta c_{t+1}\right\}\right)\right)
\end{aligned}
$$

and plug the solution (20) for $v_{t}^{1}$ and the dynamic specification for consumption growth (2) to recover a linear solution to $s_{t, t+1}^{1}$ that depends only on the state $x_{t}$ and the shock vector $\varepsilon_{t+1}$ :

$$
s_{t, t+1}=\mu_{s}+U_{s} x_{t}+\lambda_{s} \varepsilon_{t+1},
$$


where

$$
\begin{aligned}
& \mu_{s}=\log \beta-\mu_{c}-(1-\gamma)^{2} \frac{\left|\lambda_{c}+\beta U_{c}(I-\beta G)^{-1} H\right|^{2}}{2} \\
& U_{s}=-U_{c} \\
& \lambda_{s}=-\gamma \lambda_{c}+(1-\gamma) \beta U_{c}(I-\beta G)^{-1} H .
\end{aligned}
$$

The expected value of $s_{t, t+1}^{1}$ is given by the logarithm of the subjective discount $\beta$ minus the conditional mean of consumption growth and a Jensen inequality adjustment. The innovations to $s_{t, t+1}^{1}$ are decomposed to emphasize the different sources of variation to the stochastic discount factor generated by Epstein-Zin preferences as

$$
\left(\mathbb{E}_{t+1}-\mathbb{E}_{t}\right) s_{t, t+1}^{1}=\left(\lambda_{s}^{\mathrm{crra}}+\lambda_{s}^{\mathrm{ez}}\right) \varepsilon_{t+1}
$$

where

$$
\begin{aligned}
\lambda_{s}^{\mathrm{crra}} & =-\gamma \lambda_{c}, \\
\lambda_{s}^{\mathrm{ez}} & =(1-\gamma) \beta U_{c}(I-\beta G)^{-1} H .
\end{aligned}
$$

The first component $\lambda_{s}^{\text {crra }}$ is familiar in CCAPM models: it reflects the response of the stochastic discount factor to shocks as minus the product of the risk aversion parameter $\gamma$ and the exposure of consumption growth $\lambda_{c}$. The second term $\lambda_{s}^{\mathrm{ez}}$ is specific to the Epstein-Zin preference class and is given by the product of the discounted long run exposure of consumption to risk and the difference between the intertemporal elasticity of substitution, which is equal to one in this case, and the risk aversion coefficient.

We obtain an approximation of the logarithm of the stochastic discount factor $s_{t, t+1}^{\rho}$ using, as in the case of the continuation value, a Taylor expansion around the solution obtained for $\rho=1$ :

$$
s_{t, t+1}^{\rho}=s_{t, t+1}^{1}+(\rho-1) D s_{t, t+1}^{1} .
$$

The formulas for the above approximation are given in the appendix. To obtain a temporal structure of risk premia we need a stochastic discount factor $S_{t, t+j}$ that expresses the time $t$ value of payoffs paid $j$ periods ahead. The solution of the representative agent's problem also satisfies the Euler equation:

$$
\mathbb{E}_{t}\left[S_{t, t+j} R_{t, t+j}\right]=1,
$$


where $R_{t, t+j}$ is the gross return obtained from $t$ to $t+j$ and

$$
\begin{aligned}
S_{t, t+j} & =\prod_{i=1}^{j} S_{t+j-1, t+j} \\
& =\exp \left(j \mu_{s}+U_{s} \sum_{i=1}^{j} x_{t+i-1}+\lambda_{s} \sum_{i=1}^{j} \varepsilon_{t+i}\right) .
\end{aligned}
$$

\subsection{Pricing}

The temporal structure of returns can be obtained using pricing operators that transform future payoffs in current prices, generating an iterative method to compute the risk premium of dividends paid in alternative horizons. These operators encodes both short and long run properties of asset prices, illustrating the discounting dynamics determined by the stochastic discount factor.

When aggregate consumption is predictable, risk prices and exposures do not grow proportionally with time as in the i.i.d. case, as a consequence of the stationary component of consumption and dividends obtained from the Beveridge and Nelson decomposition. The deterministic trend and the martingale component, on the other hand, have simple pricing structures, and can be detached from the cash flow process to simplify the construction of the pricing operator. Define the auxiliary process $D_{t}^{*}$ by

$$
D_{t+1}^{*}=D_{t}^{*} \exp \left(\mu_{d}+\pi_{d} \varepsilon_{t+1}\right)
$$

where $D_{0}^{*}=1$. The dividend growth process can then be written as

$$
\frac{D_{t+1}}{D_{t}}=\frac{D_{t+1}^{*}}{D_{t}^{*}} \exp \left\{U_{d}^{*}\left(x_{t+1}-x_{t}\right)\right\} .
$$

The pricing operator is defined on a set of functions of the state variable, where the necessary domain depends on the intertemporal elasticity of substitution. When $\rho=1$, the stochastic discount factor has a log-linear structure that can be conveniently used to solve expectations using standard properties of lognormal variables. If $\rho$ is not unitary, we must define the domain of the pricing operator on a wider set composed by the exponential of linear quadratic functions, as the logarithm of the stochastic discount factor approximation is linear quadratic on the state. The general domain can thus be determined for functions of the form

$$
\exp \left(\phi_{0}+\phi_{1} x+\frac{1}{2} x^{\prime} \phi_{2} x\right) .
$$


Given a function determined by $\left(\phi_{0}, \phi_{1}, \phi_{2}\right)$, the pricing operator value $\mathcal{P}\left(\exp \left\{\phi_{0}+\phi_{1} x+\frac{1}{2} x^{\prime} \phi_{2} x\right\}\right)$ is defined by

$$
\begin{aligned}
& \mathcal{P}\left(\exp \left\{\phi_{0}+\phi_{1} x+\frac{1}{2} x^{\prime} \phi_{2} x\right\}\right)=\mathbb{E}\left[\operatorname { e x p } \left(s_{t, t+1}+\mu_{d}+\pi_{d} \varepsilon_{t+1}\right.\right. \\
&\left.\left.+\phi_{0}+\phi_{1} x_{t+1}+\frac{1}{2} x_{t+1}^{\prime} \phi_{2} x_{t+1}\right) x_{t}=x\right] .
\end{aligned}
$$

Each operator is dictated by the stochastic discount factor $s_{t, t+1}$ and the permanent component of dividends $\mu_{d}+\pi_{d}$. The resulting value can be written as

$$
\mathcal{P}\left(\exp \left\{\phi_{0}+\phi_{1} x+\frac{1}{2} x^{\prime} \phi_{2} x\right\}\right)=\exp \left(\phi_{0}^{*}+\phi_{1}^{*} x+\frac{1}{2} x^{\prime} \phi_{2}^{*} x\right),
$$

where the parameters $\left(\phi_{0}^{*}, \phi_{1}^{*}, \phi_{2}^{*}\right)$ are given in the Appendix.

When $\rho=1$, we are able to compute the temporal structure of returns restricting the operator $\mathcal{P}(\cdot)$ to functions of the form $\exp \left(\phi_{0}+\phi_{1} x\right)$, where

$$
\begin{aligned}
\mathcal{P}(\exp & \left.\left\{\phi_{0}+\phi_{1} x\right\}\right) \\
& =\mathbb{E}\left[\exp \left(s_{t, t+1}+\mu_{d}+\pi_{d} \varepsilon_{t+1}+\phi_{0}+\phi_{1} x_{t+1}\right) \mid x_{t}=x\right] \\
& =\exp \left(\phi_{0}^{*}+\phi_{1}^{*} x\right)
\end{aligned}
$$

and

$$
\begin{aligned}
& \phi_{0}^{*}=\mu_{s}+\mu_{d}+\phi_{0}+\frac{\left|\lambda_{s}+\pi_{d}+\phi_{1} H\right|^{2}}{2}, \\
& \phi_{1}^{*}=U_{s}+\phi_{1} G .
\end{aligned}
$$

The price in $t$ of a one period ahead dividend paying

$$
D_{t+1}^{*} \exp \left(\phi_{0}+\phi_{1} x_{t+1}+\frac{1}{2} x_{t+1}^{\prime} \phi_{2} x_{t+1}\right)
$$

can be written as

$$
\begin{aligned}
\mathbb{E}_{t}\left[S _ { t , t + 1 } D _ { t + 1 } ^ { * } \operatorname { e x p } \left(\phi_{0}+\phi_{1} x_{t+1}+\right.\right. & \left.\left.\frac{1}{2} x_{t+1}^{\prime} \phi_{2} x_{t+1}\right)\right]= \\
& D_{t}^{*} \mathcal{P}\left(\phi_{0}+\phi_{1} x_{t+1}+\frac{1}{2} x_{t+1}^{\prime} \phi_{2} x_{t+1}\right) .
\end{aligned}
$$

The price in $t$ of a payoff paid $j$ periods ahead can be obtained by repeated iteration of the operator $\mathcal{P}(\cdot)$. Suppose that an asset is determined by the 
permanent component $D_{t}^{*}$ and the transitory term (48). It's price is equal to

$$
\begin{array}{r}
\mathbb{E}_{t}\left[S_{t, t+j} D_{t+j}^{*} \exp \left\{\sum_{i=1}^{j}\left(\phi_{0}+\phi_{1} x_{t+i}+\frac{1}{2} x_{t+i}^{\prime} \phi_{2} x_{t+i}\right)\right\}\right] \\
=D_{t}^{*} \mathbb{E}_{t}\left[\operatorname { e x p } \left(\sum _ { i = 1 } ^ { j - 1 } \left(\mu_{s}+\mu_{d}+U_{s} x_{t+i-1}+\lambda_{s} \varepsilon_{t+i}+\pi_{d} \varepsilon_{t+i}+\phi_{0}\right.\right.\right. \\
\left.\left.\left.+\phi_{1} x_{t+i}+\frac{1}{2} x_{t+i}^{\prime} \phi_{2} x_{t+i}\right)\right) \mathcal{P}\left(\phi_{0}+\phi_{1} x_{t+j}+\frac{1}{2} x_{t+j}^{\prime} \phi_{2} x_{t+j}\right)\right] \\
=D_{t}^{*} \mathcal{P}^{j}\left(\phi_{0}+\phi_{1} x_{t}+\frac{1}{2} x_{t}^{\prime} \phi_{2} x_{t}\right) .
\end{array}
$$

We also define an operator $\mathcal{G}(\cdot)$ to compute expected values of future dividend levels. We can restrict the domain of this operator to log-linear functions of the state given the simple structure of dividend dynamics. For a function $\exp \left(\phi_{0}+\phi_{1} x\right)$, define $\mathcal{G}\left(\exp \left\{\phi_{0}+\phi_{1} x\right\}\right)$ as

$$
\mathcal{G}\left(\exp \left\{\phi_{0}+\phi_{1} x\right\}\right)=\mathbb{E}\left[\exp \left(\mu_{d}+\pi_{d} \varepsilon_{t+1}+\phi_{0}+\phi_{1} x_{t+1}\right) \mid x_{t}=x\right]
$$

We can use the above operator to compute the expected value, conditional on information in time $t$, of future dividends:

$$
\begin{aligned}
\mathbb{E}_{t} & {\left[D_{t+j}\right]=D_{t} \mathbb{E}_{t}\left[\exp \left\{j \mu_{d}+\sum_{i=1}^{j}\left(U_{d}^{*} \Delta x_{t+i}+\pi_{d} \varepsilon_{t+i}\right)\right\}\right] } \\
& =D_{t} \mathbb{E}_{t}\left[\exp \left\{(j-1) \mu_{d}+\sum_{i=1}^{j-1}\left(U_{d}^{*} \Delta x_{t+i}+\pi_{d} \varepsilon_{t+i}\right)\right\} \mathcal{G}\left(U_{d}^{*} \Delta x_{t+i-1}\right)\right] \\
& =D_{t} \mathcal{G}^{j}\left(U_{d}^{*} \Delta x_{t+1}\right) .
\end{aligned}
$$

Using $\mathcal{P}$ and $\mathcal{G}$, we are able to write the expected return of a dividend $D_{t+j}$ as

$$
\mathbb{E}_{t}\left[R_{t+j}\right]=\frac{\mathbb{E}_{t}\left[D_{t+j}\right]}{\mathbb{E}_{t}\left[S_{t, t+j} D_{t+j}\right]}=\frac{\mathcal{G}\left(U_{d}^{*} \Delta x_{t}\right)}{\mathcal{P}\left(U_{d}^{*} \Delta x_{t}\right)}
$$

The risk free rate, contracted in $t$, for $j$ periods ahead can easily be calculated by

$$
R_{t, t+j}^{f}=\frac{1}{\mathbb{E}\left[S_{t, t+j}\right]}=\frac{1}{D_{t}^{*} \mathcal{P}\left(U_{d}^{*} \Delta x_{t}\right)} .
$$

We can extract the long run properties of these operators using the methodology described in Hansen et al. (2008). To simplify the analysis here, we focus 
on the unitary intertemporal elasticity of substitution case. We start extracting the eigenvalue $\nu$ and eigenfuntion $\exp \left(\bar{\phi}_{0}+\bar{\phi}_{1} x\right)$ of $\mathcal{P}$ :

$$
\mathcal{P}\left(\exp \left\{\bar{\phi}_{0}+\bar{\phi}_{1} x\right\}\right)=e^{-\nu} \exp \left(\bar{\phi}_{0}+\bar{\phi}_{1} x\right)
$$

The solution of the above equation is given by

$$
\begin{aligned}
\bar{\phi}_{0} & =0, \\
\bar{\phi}_{1} & =U_{s}(I-G)^{-1}, \\
-\nu & =\mu_{s}+\mu_{d}+\frac{\left|\lambda_{s}+\pi_{d}+\bar{\phi}_{1} H\right|^{2}}{2} .
\end{aligned}
$$

The eigenfunction of the operator $\mathcal{G}(\cdot)$ is a constant given by $\phi_{0}=0$ and $\phi_{1}=0$, and the eigenvalue $\eta$ is equal to

$$
\eta=\mu_{d}+\frac{\left|\pi_{d}\right|}{2}
$$

In Hansen et al. (2008), it is shown that the limiting expected return when the horizon of dividend approaches infinity is equal to

$$
\mathbb{E}_{t}\left[R_{t, \infty}\right]=\eta+\nu=\varsigma^{*}+\pi^{*} \cdot \pi_{d}
$$

where

$$
\begin{gathered}
\varsigma=-\mu_{s}-\frac{\left|\pi_{s} \cdot \pi_{s}\right|^{2}}{2} \\
\pi_{s}=-\lambda_{s}-U_{s}(I-G)^{-1} H,
\end{gathered}
$$

where we denote $\lim _{t \rightarrow \infty} \mathbb{E}_{t}\left[R_{t, t+j}\right]=\mathbb{E}_{t}\left[R_{t, \infty}\right]$. A similar result is obtained for the long run risk free rate:

$$
\mathbb{E}_{t}\left[R_{t, \infty}\right]=\varsigma
$$

\section{Model Estimation}

In this section, we describe some statistical properties of our Brazilian macroeconomic and financial data. We investigate if consumption and GDP are cointegrated, sharing a common trend, so we can specify correctly the VAR model used to estimate dynamics. We also inspect the predictability and persistence of consumption growth, a central ingredient of the long run model. Finally, we estimate our VAR specification and identify independent permanent and 
temporary shocks. To identify permanent shocks in our dynamic system, we employ the Blanchard and Quah (1989) identification scheme. We impose that one of the two shocks in our system has no long run effect on consumption levels, so that the cumulated effect on consumption growth is equal to zero as time approaches infinity.

\subsection{Data Description}

Quarterly series for Brazilian real aggregate family consumption and gross domestic product (GDP) from 1996.I to 2015.IV are obtained from IBGE database. The two series are treated for seasonal effects. We use GDP as a predictor of future consumption growth and as an alternative source of variation allowing us to identify an additional shock. The permanent income hypothesis suggests that consumption and income are cointegrated, indicating a useful restriction to predict consumption. However, aggregate disposable income data is not available before 2000, so we selected GDP as a proxy. We obtained annual population data from 1996 to 2013 from IBGE and extrapolated from 2014 to 2015 using linear methods, as Slpine procedures generated unreliable near zero population growth. To generate a quarterly population series, we interpolated the annual data using cubic Spline methods.

Financial data is obtained using the Economatica software. We obtain a quarterly series between 1996.I and 2015.IV for IBOVESPA index to compute market returns and the SELIC rate, used as a proxy for the risk free rate. Both series are deflated using the IGP-DI price index.

Table 1 presents descriptive statistics for each series, where the mean and standard deviation estimates are annualized to simplify comparison with other studies and databases. The annualized standard deviation of consumption and

Table 1. Sample Moments.

\begin{tabular}{lrrr}
\hline Series & Mean (\%) & St. Dev. $(\%)$ & AC $(1)$ \\
\hline Consumption growth & 1.65 & 5.44 & 0.27 \\
Gdp growth & 1.29 & 5.12 & 0.22 \\
Return & 8.09 & 65.50 & 0.11 \\
Risk Free Rate & 7.16 & 9.27 & 0.55 \\
Excess Return & 0.94 & 64.69 & 0.08 \\
\hline
\end{tabular}

Note: Annualized mean and standard deviation statistics.

GDP growth are $5.44 \%$ and $5.12 \%$ respectively. As is the case in many developing 
countries, see e.g. Aguiar and Gopinath (2007), consumption is more volatile than GDP in our sample. Both series are also smoother in our database than usually reported in the Brazilian equity premium literature, see e.g. Cysne (2006) for a somewhat outdated survey, where the reported annualized standard deviation for consumption and GDP growth are at least two times higher than in our series. Aside from representing different databases, quarterly consumption and GDP growth are commonly used without seasonal adjustment, increasing their volatility. Older series are also affected by high inflation levels observed before the beginning of our sample in 1996, amplifying possible measurement error issues regarding price indexes and deflators, and resulting in larger volatilities.

Consumption and GDP growth have been low on average during the period, which are marked by relative stagnation during the end of the 90's and from 2010 onward, as we can see in Figure 1. The first order autocorrelations of consumption and GDP growth are 0.27 and 0.22 respectively, suggesting that they may be predictable by past observations, which will be tested properly.

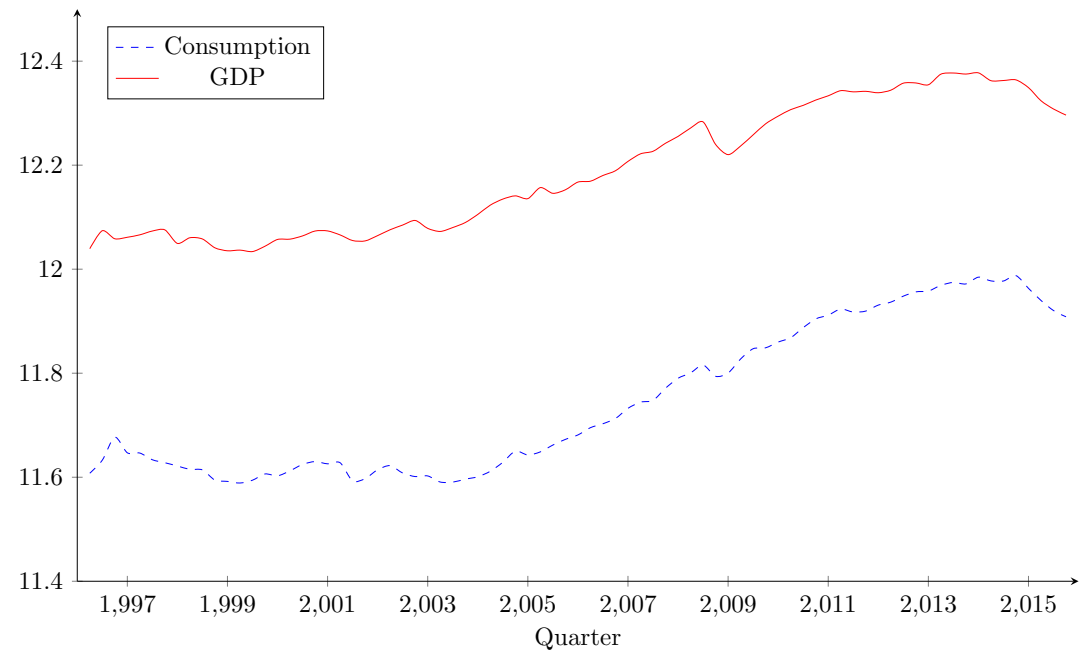

Figure 1. Logarithm of aggregate consumption and GDP.

\subsection{Statistical Properties}

We investigate some statistical properties of the logarithm of consumption $c_{t}$ and GDP, which we denote by $y_{t}$, series in order to specify a VAR model describing their dynamics. We first test for the presence of unit riots in the logarithm of consumption and GDP, applying a standard Augmented Dick Fuller (ADF) test. 
For a given sample $\left\{a_{t}\right\}$, the methodology consists in regressing

$$
\Delta a_{t}=\alpha+\delta t+\rho a_{t-1}+\beta_{1} \Delta a_{t-1}+\cdots+\beta_{p} \Delta a_{t-p}+v_{t}
$$

and testing the null hypothesis that $\rho=0$; if we cannot reject the null, we assume the series $\left\{a_{t}\right\}$ contains a unit riot. To completely specify the test, we assign the number of lags $p$ in equation (72) using the Schwarz information criterion.

Table 2 presents the results of the ADF test under two specifications for the time trend in regression (72), either including the time trend in one of the tests and restricting the parameter $\delta$ to be equal to zero in the other. The results indicate that we cannot reject at the $5 \%$ level of significance that both consumption and GDP have an unit riot.

We now investigate possible cointegration between $c_{t}$ and $y_{t}$. Figure 1, plotting the logarithm of consumption and GDP, appears to suggest that the series share a common stochastic trend. The permanent income hypothesis, see e.g. Campbell (1987), also implies that consumption and income should be cointegrated, with $(1,-1)$ as the cointegrating vector. We test the cointegration hypothesis in our sample using GDP as a proxy for income. In Figure 2, we plot the difference $y_{t}-c_{t}$, which should be stationary in case of cointegration.

To properly verify if $y_{t}-c_{t}$ is stationary, we apply two different tests. We first test if the difference $y_{t}-c_{t}$ has a unit riot using the ADF procedure, which is valid if the cointegrating vector is known. Results are presented in Table 3, showing that we cannot reject the null hypothesis that there is an unit riot in $y_{t}-c_{t}$. This results indicate that aggregate consumption and GDP are not cointegrated in Brazil.

The second test is an application of the Johansen (1991) procedure using either an unrestricted model for $y_{t}-\omega c_{t}$, where $\omega$ is freely estimated, and the restriction $(1,-1)$ for the cointegrating vector. Results in Table 4 are not

Table 2. Testing for Unit Roots.

\begin{tabular}{lrrrrr}
\hline \multirow{2}{*}{ Series } & \multicolumn{2}{c}{ Time Trend } & & \multicolumn{2}{c}{ No Time Trend } \\
\cline { 2 - 3 } \cline { 5 - 6 } Consumption & t-statistics & p-value & & t-statistics & p-value \\
GDP & -0.24 & 0.93 & & -1.90 & 0.64 \\
\cline { 1 - 2 } & -0.60 & 0.86 & & -1.99 & 0.59 \\
\hline
\end{tabular}

Notes: Testing for unit riot using ADF procedure. Lags are chosen under Schwartz criteria. 


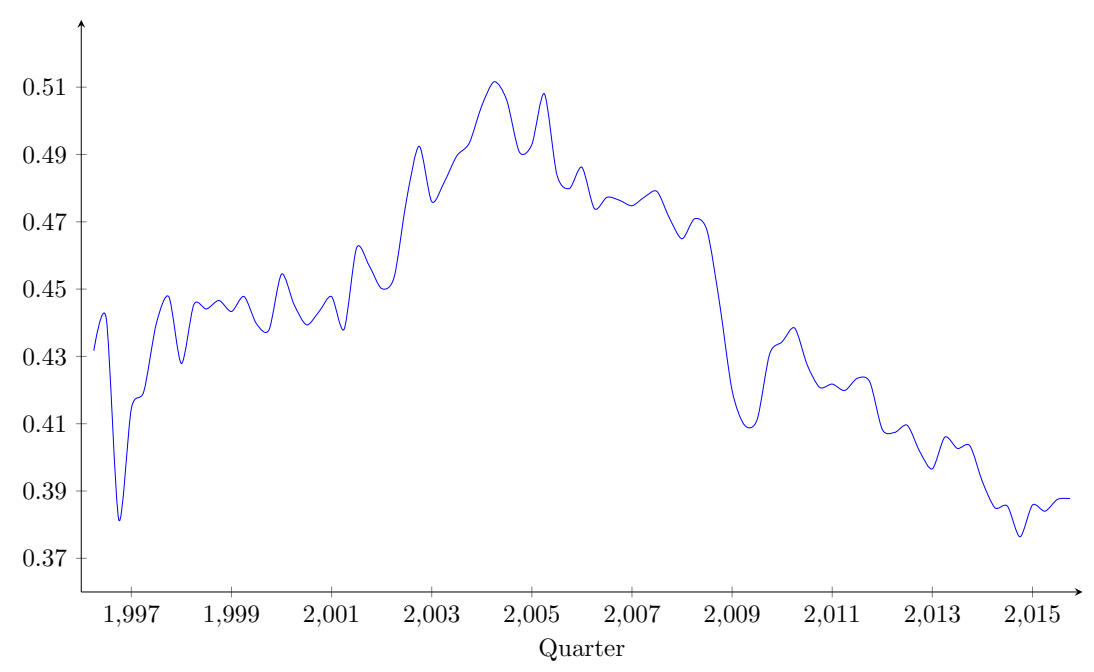

Figure 2. Difference between the logarithms of consumption and GDP.

Table 3. Testing for Cointegration.

\begin{tabular}{crrrrr}
\hline \multirow{2}{*}{ Series } & \multicolumn{2}{c}{ Time Trend } & & \multicolumn{2}{c}{ No Time Trend } \\
\cline { 2 - 3 } \cline { 5 - 6 } & t-statistics & p-value & & t-statistics & p-value \\
\hline$y_{t}-c_{t}$ & -1.23 & 0.65 & & -1.88 & 0.65 \\
\hline
\end{tabular}

Notes: Testing for unit riot using ADF procedure. Lags are chosen under Schwartz criteria.

Table 4. Cointegration Tests.

\begin{tabular}{|c|c|c|c|}
\hline \multicolumn{4}{|c|}{ Unrestricted Cointegration Test } \\
\hline $\begin{array}{l}\text { Number of } \\
\text { Cointegrating relations }\end{array}$ & Trace statistics & 0.05 crit. value & p-value \\
\hline 0 & 10.69 & 15.49 & 0.23 \\
\hline At most one & 1.36 & 3.84 & 0.24 \\
\hline \multicolumn{4}{|c|}{ Restricted Cointegration Test } \\
\hline $\begin{array}{l}\text { Cointegrating } \\
\text { vector restriction }\end{array}$ & LR statistics & 0.05 crit. value & p-value \\
\hline$\left[\begin{array}{ll}1 & -1\end{array}\right]$ & 5.43 & 3.84 & 0.019 \\
\hline
\end{tabular}


conclusive, we cannot reject that there is no cointegration, but we also cannot reject the hypothesis that there is one cointegrating relation, either in the restricted and unrestricted tests.

\subsection{Predictability}

In this section, we present predictability results for consumption growth, the key ingredient for the long run risks model. We start by analyzing consumption growth predictability using its past observations and GDP growth $\Delta y_{t}$ as predictors:

$$
\Delta c_{t}=\alpha+\beta_{1} \Delta c_{t-1}+\beta_{2} \Delta y_{t-1}+u_{t}
$$

We use GDP growth as predictor so we are able to identify two independent shocks when estimating a full VAR system for our economy. Results are summarized in Table 5 and shows that consumption growth in one quarter ahead can be predicted by past consumption and GDP growth with an $R^{2}$ of 0.17 .

Table 5. Consumption Growth Predictability.

\begin{tabular}{lccc}
\hline Predicted variable & $\boldsymbol{\Delta} \mathbf{c}_{\mathbf{t}-\mathbf{1}}$ & $\mathbf{\Delta} \mathbf{y}_{\mathbf{t}-\mathbf{1}}$ & $\mathbf{R}^{\mathbf{2}}$ \\
\hline$\Delta c_{t}$ & 0.07 & 0.39 & 0.17 \\
& $(0.61)$ & $(3.02)$ & \\
$\Delta c_{t}+\Delta c_{t+1}$ & 0.27 & 0.24 & 0.07 \\
& $(1.33)$ & $(1.12)$ & \\
$\sum_{i=0}^{3} \Delta c_{t+i}$ & 0.20 & 0.62 & 0.04 \\
& $(0.62)$ & $(1.25)$ & \\
\hline
\end{tabular}

Notes: We regress $a_{t}=\alpha+\beta_{1} \Delta c_{t-1}+\beta_{2} \Delta y_{t-1}+u_{t}$, where $a_{t}$ stands for the variable in the left column of the table. The t-statistics are presented in parenthesis.

Although the predictability is not strong, it is consistent with the international literature, where consumption growth tends to resemble a random walk.

Even though past consumption and GDP help to predict one quarter ahead consumption growth, this ability drops with time to a $R^{2}$ of 0.07 for two quarters ahead and 0.04 a year ahead prediction. This result indicate that consumption growth, despite being predictable in the short run, may not have a persistent dynamics.

We test if incorporating the risk free rate as predictor improves the consumption growth predictability. The SELIC rate is used by the Brazilian central bank as an instrument to influence inflation and growth, potentially containing new 
information to forecast consumption growth. We run the following regression:

$$
\Delta c_{t}=\alpha+\beta_{1} \Delta c_{t-1}+\beta_{2} \Delta y_{t-1}+\beta_{3} R_{t-1}^{f}+u_{t},
$$

where $R_{t}^{f}$ represents the risk free rate. Results are in Table 6. As we can see, the risk free rate is not useful to predict future consumption growth after past consumption and GDP growth are accounted for. This result indicate that eliminating the risk free rate as a predictor, as we do in the next session to identify independents shocks, does not have a significant impact on describing consumption dynamics.

We also test the consequences of imposing conintegration to consumption and GDP to the prediction of consumption growth. The idea is that if the series are cointegrated, $y_{t}-c_{t}$ is stationary and differences between GDP and consumption carry new information about future consumption growth. We first estimate a regression on

$$
\Delta c_{t}=\alpha+\beta_{1} \Delta c_{t-1}+\beta_{2}\left(y_{t-1}-c_{t-1}\right)+u_{t}
$$

The above specification represents a detached equation of a cointegrated VAR system in triangular form. We prefer this approach to incorporate cointegration to simplify interpretation and comparison of results in the asset pricing section. Table 7 summarizes the results, indicating that imposing cointegration does not improve prediction of consumption growth in the short run, as the $R^{2}$ is equal to 0.15 , but adds new information to the forecast of consumption in longer horizons. The $R^{2}$ in the regressions for two quarters and one year ahead are 0.18 and 0.24 respectively.

Table 6. Consumption Growth Predictability.

\begin{tabular}{lcccc}
\hline Predicted variable & $\boldsymbol{\Delta} \mathbf{c}_{\mathbf{t}-\mathbf{1}}$ & $\mathbf{\Delta} \mathbf{y}_{\mathbf{t}-\mathbf{1}}$ & $\boldsymbol{\Delta} \mathbf{r}_{\mathbf{t}-\mathbf{1}}$ & $\mathbf{R}^{\mathbf{2}}$ \\
\hline$\Delta c_{t}$ & 0.07 & 0.42 & 0.06 & 0.18 \\
& $(0.49)$ & $(3.14)$ & $(0.95)$ & \\
$\Delta c_{t}+\Delta c_{t+1}$ & 0.28 & 1.17 & 0.04 & 0.07 \\
& $(1.32)$ & $(1.12)$ & $(0.42)$ & \\
$\sum_{i=0}^{3} \Delta c_{t+i}$ & 0.20 & 0.42 & 0.00 & 0.04 \\
& $(0.61)$ & $(1.21)$ & $(0.004)$ & \\
\hline
\end{tabular}

Notes: We regress $a_{t}=\alpha+\beta_{1} \Delta c_{t-1}+\beta_{2} \Delta y_{t-1}+\beta_{3} r_{t-1}^{f}+u_{t}$, where $a_{t}$ stands for the variable in the left column of the table. The t-statistics are presented in parenthesis. 
Table 7. Consumption Growth Predictability.

\begin{tabular}{lccc}
\hline Predicted variable & $\mathbf{\Delta} \mathbf{c}_{\mathbf{t}-\mathbf{1}}$ & $\mathbf{y}_{\mathbf{t}-\mathbf{1}}-\mathbf{c}_{\mathbf{t}-\mathbf{1}}$ & $\mathbf{R}^{\mathbf{2}}$ \\
\hline$\Delta c_{t}$ & 0.23 & 0.11 & 0.15 \\
& $(2.16)$ & $(2.71)$ & \\
$\Delta c_{t}+\Delta c_{t+1}$ & 0.31 & 0.21 & 0.18 \\
& $(1.94)$ & $(3.50)$ & \\
$\sum_{i=0}^{3} \Delta c_{t+i}$ & 0.45 & 0.44 & 0.24 \\
& $(1.65)$ & $(4.51)$ & \\
\hline
\end{tabular}

Notes: We regress $a_{t}=\alpha+\beta_{1} \Delta c_{t-1}+\beta_{2}\left(y_{t-1}-c_{t-1}\right)+u_{t}$, where $a_{t}$ stands for the variable in the left column of the table. The t-statistics are presented in parenthesis.

\subsection{Consumption Dynamics}

Having analysed the stochastic relations between consumption and GDP, we specify dynamic models to identify long run shocks. We estimate consumption dynamics under a VAR framework, using consumption and GDP growth as endogenous variables. We do not impose cointegration do avoid misspecification problems in light of our results in subsection 3.2. Define $z_{t}=\left(\Delta c_{t}, \Delta y_{t}\right)$ and write it as a $\operatorname{VAR}(p)$ :

$$
z_{t}=\mu+\Phi_{1} z_{t-1}+\ldots+\Phi_{p} z_{t-p}+u_{t}
$$

where the matrices $\Pi$ and $\Phi_{i}$ are $2 \times 2$, for $i=1, \ldots, p ; \mu$ is a 2-dimensional vector; and $u_{t+1}$ has zero mean and covariance matrix $\Omega$. The number of lags is chosen according to the Schwarz criterion in the first place, where new lags are added if necessary to avoid residual autocorrelation. The covariance matrix of residuals $\Omega$ does not have economic meaning, specially since residuals are correlated in our sample.

To identify independent shocks that have economic interpretation in our long run risks environment, we apply Blanchard and Quah (1989) decomposition. The identification consists in assuming that structural shocks $\varepsilon_{t+1}=\left(\varepsilon_{t+1}^{t}, \varepsilon_{t+1}^{p}\right)$ are uncorrelated with each other and only one of them, $\varepsilon_{t+1}^{p}$, has permanent effects on consumption level. The identifying restriction is that the cumulated effect of $\varepsilon_{t+1}^{t}$ on future consumption growth is equal to zero when time approaches infinity. The VAR system allows us to recover estimated short run risk exposures of aggregate consumption growth $\lambda_{c}$ from long run restrictions. We distinguish each coordinate of vector $\lambda_{c}$ by defining $\lambda_{c}^{t}$ as the short run effect to the temporary 
shock and $\lambda_{c}^{p}$ as the short run effect caused by the permanent shock.

We assume that dividends have levered exposures to consumption risks, so that the vectors $\lambda_{d}$ and $\lambda_{c}$ are proportional. Similar to Bansal and Yaron (2004), we assume that $\lambda_{d}=4 \lambda_{c}$, where it is implied that the leverage on each structural shock is the same. The choice of leverage, although important to the determination of total risk premium, does not impact risk prices or the relative importance of cash flow risk exposure. We also select a leverage that does not artificially inflate excess returns, but at the same time acknowledges the fact that dividend growth variation tends to be much higher than the one found on consumption growth. Campbell (2003), using international data, finds that dividend growth's standard deviation is between 1.7 and 16 times higher than the consumption growth counterpart.

Using equations (5) and (14), we obtain estimates for the long run cumulated effects of shocks to consumption $\pi_{c}$ and dividend $\pi_{d}$. We adopt the same terminology used above and define $\pi_{i}^{t}$ and $\pi_{i}^{p}$ as the long run responses to temporary and permanent shocks, respectively, where $i$ stands for $c$ or $d$. Table 8 reports estimation results for both short and long run risk exposures. We multiply every result by 100 to obtain percentage responses to a one standard deviation shock.

Permanent shocks are the primary source of variation to aggregate consumption and dividends. The short run response of consumption growth to the permanent shock is $1.22 \%$, about 3.5 times higher than the one quarter risk exposure of $0.34 \%$ to the temporary shock. The risk exposure patterns for dividend growth are the same as a consequence of our parametrization choice: a one standard deviation shock causes dividends to increase $4.89 \%$ after a permanent shock and $1.33 \%$ after a temporary shock. Although consumption growth in Brazil has a predictable component, it is not large, as indicated by the small size of temporary shocks. When the dynamics of consumption level is determined by a random walk, and thus is not predicted by other variables, temporary shocks cannot exist. The short run effect of a temporary shock on

Table 8. Risk Exposures.

\begin{tabular}{lcccc}
\hline Series & $\lambda_{i}^{t}(\%)$ & $\lambda_{i}^{p}(\%)$ & $\pi_{i}^{t}(\%)$ & $\pi_{i}^{p}(\%)$ \\
\hline Consumption & 0.34 & 1.22 & 0 & 1.95 \\
Dividend & 1.33 & 4.89 & 0 & 7.8 \\
\hline
\end{tabular}

Notes: Risk exposures are multiplied by 100. 
consumption has to be reversed in the future, which is not possible in a random walk scenario.

The long run consumption and dividend responses are dictated by the restrictions imposed for identification. The cumulated effect of temporary shocks in both series are equal to zero by design, as we have seen, so that expectations about consumption levels in the long run remains unchanged. The permanent shock, on the other hand, has no long run restrictions and is determinant to the asymptotic properties of consumption, dividends and asset prices. A one standard deviation permanent shock generates a $1.95 \%$ increase to consumption level in the long run, larger than the one period response, indicating some degree of predictability and persistence. The long run effect of a permanent shock to aggregate dividend under our parametrization is $7.8 \%$, a relevant risk exposure to a one quarter shock.

We depict impulse responses of consumption levels to both temporary and permanent shocks in Figure 3. The effects of temporary shocks to consumption quickly declines to zero, lasting for about two quarters. This result is explained by the small short run impact of temporary shocks, which can be easily reversed. The effect of permanent shock accumulates over time, stabilizing about one year in advance at its long run value $\pi_{c}^{p}$.

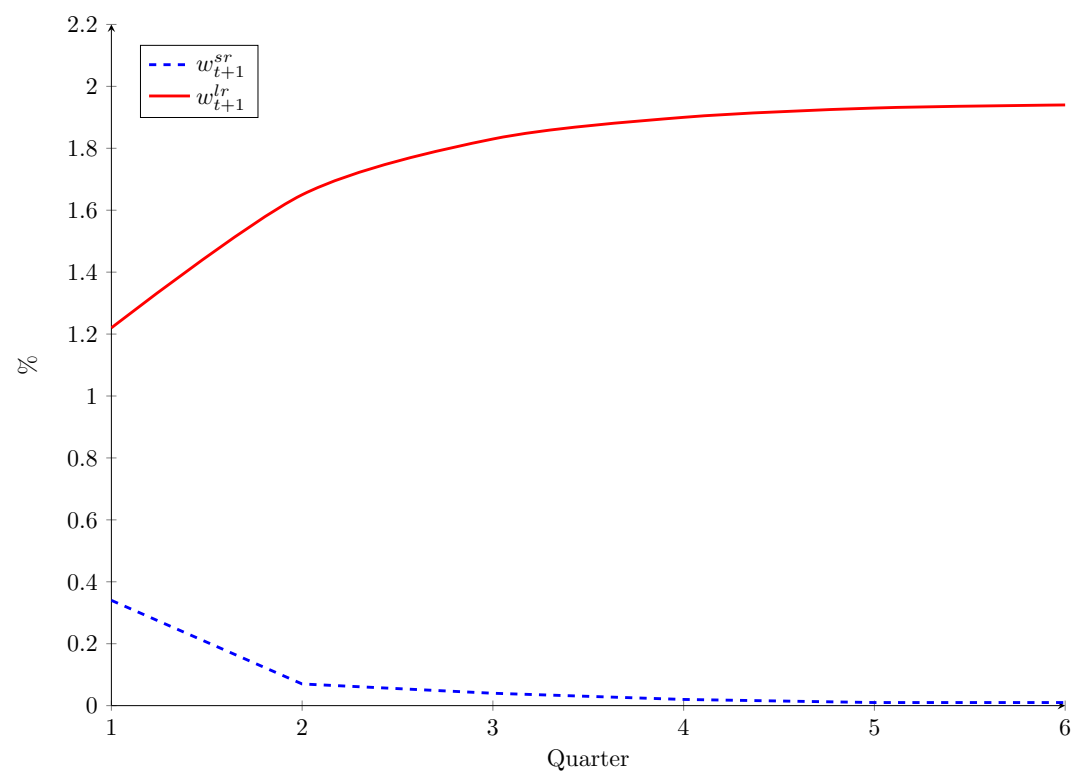

Figure 3. Consumption Impulse Responses. 
We illustrate in Figure 4 the Beveridge and Nelson decomposition of the logarithm of consumption level between a deterministic trend, a stationary process and a martingale. To simplify comparison between the three processes, we added the deterministic trend to the stationary and martingale series. The deterministic trend $\mu_{c}$ is equal to $1.55 \%$ (it is not equal to the mean logarithm consumption growth, $1.65 \%$, because of the loss of observations necessary to estimate a VAR system).

The stationary component of consumption level, given by $-U_{c}(I-G)^{-1} x_{t}$, is relatively small. To understand why this is the case in the Brazilian data, notice that an innovation to the stationary term is given by the negative of cumulated future responses to a shock on consumption growth $-U_{c}(I-G)^{-1} H$. In mathematical terms, it is the difference between $\pi_{c}$ and $\lambda_{c}$. As a consequence of our identification procedure, $\pi_{c}^{t}=0$, so the effect of an innovation to the stationary term is equal to $-\lambda_{c}^{t}=-0.34 \%$. The response of $s_{t}$ to an innovation to the permanent shock is equal to $-0.73 \%$, about twice the effect of the temporary shock, being the primary source of variation to the stationary component of consumption level.

The evolution of the martingale component $z_{t}$ is entirely determined by the permanent shock because of the restriction $\pi_{c}^{t}=0$ imposed for identification. As we can see in Figure 4, the martingale process is the main source of variations to consumption levels. This pattern is consistent with data in US, see e.g. Reis

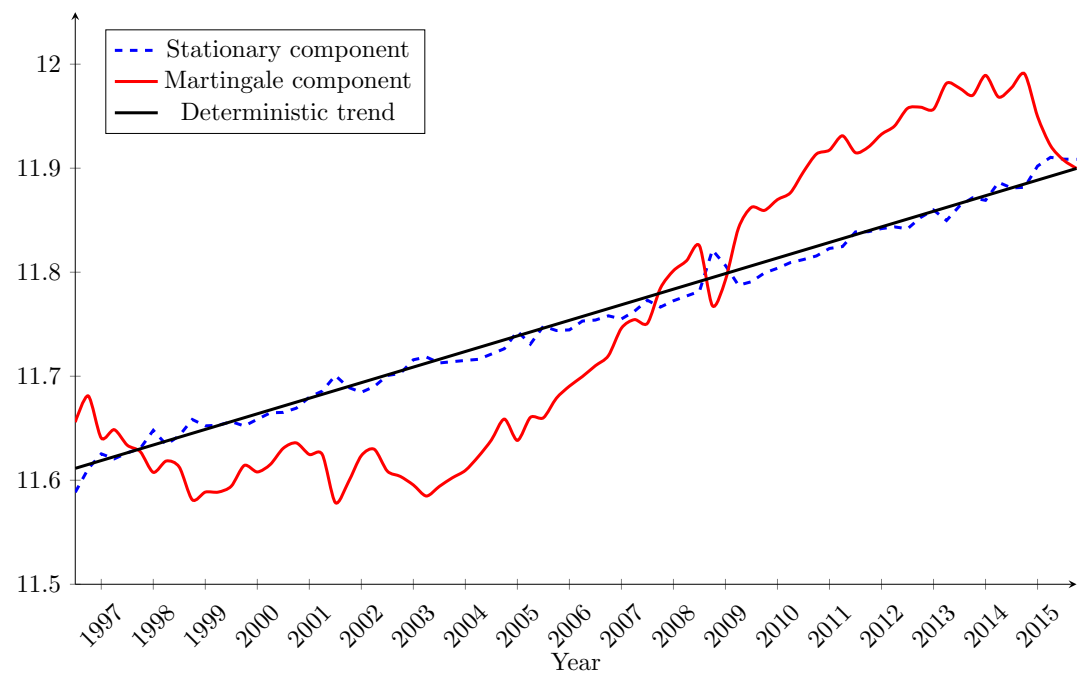

Figure 4. Beveridge and Nelson Decomposition. 
(2009), Cochrane (1994) and Bansal and Yaron (2004), in which consumption resembles a random walk, as predicted by the permanent income hypothesis, but contains a small predictive component. The effect of a permanent shock to the martingale $z_{t}$ is equal to the long run cumulated effect on consumption level, $\pi_{c}^{p}=1.95 \%$, the unrestricted element of $\pi_{c}$.

\section{Asset Pricing Implications}

Asset prices are dictated by the dynamic specification of cash flows and the stochastic discount factor, which are in turn determined by consumption, the only source of non-diversifiable risk in the model. In this section, we examine the asset pricing implications of estimated Brazilian consumption dynamics, which are used to construct stochastic processes for aggregate dividends and approximate solutions for the stochastic discount factor.

In Table 9 , we show results for risk prices $-\lambda_{s}$, the one period exposure of $s_{t, t+1}$ to risk, and $-\pi_{s}$, the long run exposure of the stochastic discount factor to uncertainty, assuming that $\rho=1$. As we have seen, in this case one period risk prices can be expressed as the sum of two sources of innovations to $s_{t, t+1}$ : a familiar CRRA component $-\lambda_{s}^{\text {crra }}=\gamma \lambda_{c}$, associated with aversion to next period consumption uncertainty by the representative agent, and $-\lambda_{s}^{\mathrm{ez}}=$ $(\gamma-1) \beta U_{c}(I-\beta G)^{-1}$, the Epstein-Zin induced risk price that reflects concerns with respect to continuation value's variations. Results in Table 9 are decomposed between risk prices associated with temporary and permanent shocks, where each term represents a coordinate of the corresponding risk price vector. The subjective discount factor $\beta$ is fixed in 0.96 .

The main source of variation in the decomposed stochastic discount factor is the usual power utility induced risk price $-\lambda_{s}^{\text {crra }}$, associated either with temporary and permanent shocks. The risk price generated by $\lambda_{s}^{\text {crra }}$ increases

Table 9. Risk Price Decomposition.

\begin{tabular}{|c|c|c|c|c|c|c|c|c|}
\hline \multirow[b]{2}{*}{$\gamma$} & \multicolumn{2}{|c|}{$-\lambda_{s}^{\mathrm{crra}}(\%)$} & \multicolumn{2}{|c|}{$-\lambda_{s}^{\mathrm{ez}}(\%)$} & \multicolumn{2}{|c|}{$-\lambda_{s}(\%)$} & \multicolumn{2}{|c|}{$-\pi_{s}(\%)$} \\
\hline & $\varepsilon_{t+1}^{t}$ & $\varepsilon_{t+1}^{p}$ & $\varepsilon_{t+1}^{t}$ & $\varepsilon_{t+1}^{p}$ & $\varepsilon_{t+1}^{t}$ & $\varepsilon_{t+1}^{p}$ & $\varepsilon_{t+1}^{t}$ & $\varepsilon_{t+1}^{p}$ \\
\hline 2 & 0.66 & 2.45 & -0.31 & 0.66 & 0.35 & 3.11 & 0.03 & 3.83 \\
\hline 5 & 1.66 & 6.12 & -1.23 & 2.64 & 0.43 & 8.75 & 0.11 & 9.47 \\
\hline 10 & 3.32 & 12.23 & -2.76 & 5.93 & 0.57 & 18.16 & 0.25 & 18.87 \\
\hline 20 & 6.64 & 24.46 & -5.81 & 12.51 & 0.84 & 36.96 & 0.51 & 37.68 \\
\hline
\end{tabular}

Notes: Risk prices are multiplied by 100 . The parameters used are $\beta=0.96$ and $\rho=1$. 
proportionally with $\gamma$, as it is represented by the product of risk aversion and the consumption growth exposure to aggregate shocks. This proportionality means that the same pattern observed in consumption takes place here: permanent shocks generate about 3.5 times more power induced risk prices than temporary shocks.

Risk prices originated by the Epstein-Zin component $-\lambda_{s}^{\mathrm{ez}}$ have distinct results depending on which shock they are referring to. We start examining permanent shocks, the main source of consumption uncertainty in the Brazilian economy. Positive permanent shocks are good news for consumption in subsequent periods, as indicated in Table 8, generating variation in the expected value of future consumption levels and inducing a response to the stochastic discounted factor through $\lambda_{s}^{\mathrm{ez}}$. Comparing this result with Table 9, we can see that the gap between $\lambda_{s}^{\mathrm{ez}}$ and $\lambda_{s}^{\mathrm{crra}}$ associated with permanent shocks increases for higher levels of risk aversion. When $\gamma=2$, the risk price induced by power utility and the permanent shock is almost four times the price generated through the Epstein-Zin component for the same source of risk. This discrepancy decreases when the risk aversion is larger: for $\gamma=20$, the risk price of the exposure to permanent shocks induced by $\lambda_{s}^{\mathrm{crra}}$ is about two times $\lambda_{s}^{\mathrm{ez}}$. These results suggest that predictability features in the Brazilian aggregate consumption dynamics are able to establish a distinction between risk prices generated by Epstein-Zin preferences and risk prices obtained using the standard power utility.

Temporary shocks generate distinct risk price patterns in this economy. Table 9 shows that the risk price of a temporary shock associated with components $\lambda_{s}^{\mathrm{crra}}$ and $\lambda_{s}^{\mathrm{ez}}$ have inverted signs but similar absolute values. To understand the rationale behind this result, we investigate more deeply the mechanisms behind the shock identification method. Identification is obtained by restricting one coordinate in $\lambda_{c}+U_{c}(I-G)^{-1} H$ to be equal to zero, so that the short run effect of a temporary shock is reversed in the future and the long run level of consumption remains unchanged. Accordingly, a positive temporary shock is bad news for future consumption growth and decreases the risk adjusted continuation value of the representative agent. Therefore, although the exposure to temporary shocks generates a positive risk price through the usual power utility channel, it also induces the opposite effect through the Epstein-Zin component, as it is determined by the discounted cumulative consumption responses.

The total risk price $-\lambda_{s}$, the sum of components $-\lambda_{s}^{\text {crra }}$ and $-\lambda_{s}^{\mathrm{ez}}$, is dominated by compensations for exposure to permanent consumption shocks, ultimately the main determinant of short run risk premia in this economy. 
Consumption uncertainty, as discussed above, is primarily driven by permanent shocks, both in the short and long run. Positive permanent shocks increase payoff discounting by decreasing marginal utilities through $\lambda_{s}^{\text {crra }}$ and, reflecting the subsequent positive effect on continuation values, reinforces payoff discounting through $\lambda_{s}^{\mathrm{ez}}$. Exposure to temporary shocks, nevertheless, have a small positive risk price because, although it decreases marginal utilities through a short term boost to consumption, it is bad news for consumption in subsequent quarters, almost completely reverting the marginal utility effect. The total risk price of a temporary shock is still positive, as reported in Table 9, because of the subjective discount $\beta$.

For $\rho=1$, long run risk prices are given by $-\pi_{s}$, as defined in equation (70). The difference between $\pi_{s}$ and $\lambda_{s}$ is given by $-U_{c}(I-G)^{-1} H$, so variations in the temporal structure of risk prices are determined by predictability and persistence of aggregate consumption. The long run risk price of the exposure to temporary shocks is near zero for all risk aversion parameters illustrated in the table, which is an expected result since consumption is not affected by these shocks in the long run. Permanent shocks, on the other hand, as the only source of long run consumption uncertainty, dictate risk compensations in the long run, as depicted in the third column of the table.

Comparing the long run risk prices with their short run counterpart in Table 9 , we find that the temporal structure of risk prices in Brazil does not change dramatically over time. This result is a consequence of the weak predictability of Brazilian consumption, as discussed in section 3. As we have seen, though, even a small predictable component in consumption is able to increase short run risk prices through the Epstein-Zin component $\lambda_{s}^{\mathrm{ez}}$, which enhances the effect of consumption predictability because of the risk aversion coefficient. The consumption dynamics in Brazil, however, is not able to produce a large gap between short and long run risk prices, where risk aversion does not play a role. A similar result is found in Hansen et al. (2008), where a mostly flat risk price temporal structure is obtained using US data.

In Table 10, we report short and long run risk free rates generated by the model using the estimated consumption dynamics. The IES does not shift risk free rates significantly, so we focus our discussion on the special case $\rho=1$ to gain intuition. All results below that are depended on conditional expectations are obtained setting the state variable $x_{t}$ to zero.

The one period risk free rate is determined by the mean and variance of $s_{t, t+1}$. When the state variable is zero, the mean logarithm of the stochastic 
Table 10. Annualized Risk Free Rate (\%).

\begin{tabular}{|c|c|c|c|c|c|c|}
\hline \multirow[b]{2}{*}{$\beta / \rho$} & \multicolumn{3}{|c|}{$r_{t, t+1}^{f}$} & \multicolumn{3}{|c|}{$r_{t, \infty}^{f}$} \\
\hline & 0.5 & 1 & 1.5 & 0.5 & 1 & 1.5 \\
\hline & \multicolumn{6}{|c|}{$\gamma=\mathbf{5}$} \\
\hline 0.99 & 4.37 & 5.10 & 5.82 & 4.23 & 4.83 & 5.43 \\
\hline 0.98 & 8.44 & 9.16 & 9.89 & 8.30 & 8.90 & 9.49 \\
\hline \multirow[t]{2}{*}{0.97} & 12.54 & 13.27 & 13.99 & 12.10 & 13.00 & 13.60 \\
\hline & \multicolumn{6}{|c|}{$\gamma=10$} \\
\hline 0.99 & 3.95 & 4.63 & 5.30 & 3.67 & 4.07 & 4.48 \\
\hline 0.98 & 8.01 & 8.69 & 9.37 & 7.74 & 8.14 & 8.55 \\
\hline \multirow[t]{2}{*}{0.97} & 12.12 & 12.80 & 13.47 & 11.85 & 12.25 & 12.66 \\
\hline & \multicolumn{6}{|c|}{$\gamma=20$} \\
\hline 0.99 & 3.09 & 3.68 & 4.25 & 2.53 & 2.56 & 2.59 \\
\hline 0.98 & 7.17 & 7.75 & 8.32 & 6.61 & 6.64 & 6.67 \\
\hline 0.97 & 11.28 & 11.86 & 12.44 & 10.73 & 10.76 & 10.79 \\
\hline
\end{tabular}

Note: Risk rates are multiplied by 100 .

dis count factor is equal to $\mu_{s}$, which is mainly dictated by the the subjective discount factor. A small change in $\beta$ represents a large shift to the annualized risk free rate: when the discount factor decreases its value by 0.01 , the annualized risk free rate increases about $4 \%$. The contribution of the unconditional mean consumption growth $\mu_{c}$ to the annualized log risk free rate is equal to $1.5 \%$. The Jensen correction is a small component of the risk free rate and is responsible for the variation detected between different coefficients of risk aversion.

The discrepancy between short and long run risk free rates is determined by the Jensen adjustment, which is given by half of the norm of the associated stochastic discount factor's exposure vector. Temporal differences related to risk free rates are small in this model mainly due to two reasons. First, the Jensen adjustment is relatively small when compared with $\mu_{s}$. Second, the short and long run rates differ only if the gap between $\left|\lambda_{s}\right|$ and $\left|\pi_{s}\right|$ is not negligible, which as we have seen is not the case. Another way to interpret this result is to notice that a non smooth risk free rate curve will only emerge if risk prices change dramatically over time, so that it's volatility compensates the limited importance of the Jensen inequality to the determination of risk free rates. Our 
results don't imply this pattern of risk price temporal structure.

To report risk premium results, we also focus on the log-linear case when $\rho=1$. If this special condition is satisfied, the model allows us to write one period risk premium as the inner product between the risk price $-\lambda_{s}$ and the risk exposure $\lambda_{d}$ for any payoff that can be described as in equation (11). We decomposed risk prices as the sum of $-\lambda_{s}^{\mathrm{crra}}$ and $-\lambda_{s}^{\mathrm{ez}}$, so we write one period excess return as the sum of the premia originated from CRRA preferences and the extra Epstein-Zin preference component. Using this decomposition, we are able to assess if the Brazilian economy presents the necessary patterns of predictability and persistence to justify the use of the more general Epstein-Zin preferences class. Define

$$
\begin{aligned}
\mathbb{E}_{t} R_{t, t+1}^{e, \mathrm{crra}} & =-\lambda_{s}^{\mathrm{crra}} \cdot \lambda_{d}, \\
\mathbb{E}_{t} R_{t, t+1}^{e, \mathrm{ez}} & =-\lambda_{s}^{\mathrm{ez}} \cdot \lambda_{d},
\end{aligned}
$$

so that we can write one period risk premium as

$$
\mathbb{E}_{t}\left[R_{t, t+1}^{e}\right]=\mathbb{E}_{t} R_{t, t+1}^{e, \mathrm{crra}}+\mathbb{E}_{t} R_{t, t+1}^{e, \mathrm{ez}}
$$

Table 11 shows results for risk premia in the log-linear case, both in the short and long run, using different parametrizations for $\beta$ and $\gamma$. Most of the risk premium in this economy is generated by the usual power utility component of the stochastic discount factor, as it is also the main source of risk prices. Epstein-Zin induced premia, however, are not negligible and constitutes about a third of the market one period excess return when the risk aversion coefficient is equal to 10 and 20. These results suggest that even though consumption predictability and persistence is relatively low in Brazil, it is still capable of generating a significant compensation for payoff risks. The model, however, in this log-linear environment, requires a relatively large risk aversion to produce a moderate risk premium for payoffs realized one period ahead.

We can also see that the subjective discount factor $\beta$ has a minor effect on risk premia. As we see in equation (41), the risk price induced by power utility $-\lambda_{s}^{\text {crra }}$ depends entirely on risk aversion and the one period ahead exposure of consumption to aggregate risks. Nevertheless, a small effect of $\beta$ can be found in $\lambda_{s}^{\mathrm{ez}}$, reflecting the influence of discounting future consumption levels to compose continuation values. When $\beta$ is low, future consumption streams are less important to the representative agent and the effect of news about future consumption to the stochastic discount factor is constrained. A consequence 
Table 11. Annualized Equity Premium (\%).

\begin{tabular}{lcccc}
\hline $\boldsymbol{\beta}$ & $\mathbb{E}_{t} R_{t, t+1}^{e, \mathrm{crra}}$ & $\mathbb{E}_{t} R_{t, t+1}^{e, \mathrm{ez}}$ & $\mathbb{E}_{t} R_{t, t+1}^{e}$ & $\mathbb{E}_{t} R_{t, \infty}^{e}$ \\
\hline 0.97 & 1.28 & 0.47 & 1.75 & \\
0.98 & 1.28 & 0.48 & 1.76 & 2.16 \\
0.99 & 1.28 & 0.49 & 1.77 & 2.17 \\
\hline & & \multicolumn{2}{c}{$\boldsymbol{\gamma}=\mathbf{1 0}$} & \\
\hline 0.97 & 2.56 & 1.06 & 3.63 & 4.31 \\
0.98 & 2.56 & 1.08 & 3.65 & 4.34 \\
0.99 & 2.56 & 1.1 & 3.67 & 4.36 \\
\hline & & & & \\
\hline 0.97 & 5.13 & 2.25 & $\mathbf{2 0}$ & 7.39 \\
0.98 & 5.13 & 2.29 & 7.43 & 8.67 \\
0.99 & 5.13 & 2.33 & 7.47 & 8.72 \\
\hline
\end{tabular}

Note: Annualized returns are multiplied by 100 .

of lower $\beta$ is thus a reduced variation in $s_{t, t+1}$ and a lower compensation for one period ahead payoffs that are impacted by news about future consumption growth.

As we have discussed above, the risk exposure of consumption to shocks is not i.i.d., which would add the same amount of risk every period. The consumption predictability pattern found in the Brazilian data implies that permanent shocks, the main source of long run risks, accumulates over time and exposes the representative agent to more uncertainty when the payoff is paid further in the future. Risk prices also tend to accumulate over time, as we have seen in Table 9, boosting the compensation required to bear long run risks.

In Table 12, we fix $\beta=0.98$ and examine the effect of the intertemporal elasticity of substitution on one period risk premium. The results suggest a small influence of $\rho$ in the determination of the equity premium. We must keep in mind, though, that the range of $\rho$ is relatively small as we are working with approximations of the stochastic discount factor around $\rho=1$, which restrains the use of larger IES values. 
Table 12. One Period Excess Return.

\begin{tabular}{cccc}
\hline & \multicolumn{3}{c}{$\mathbb{E}_{t}\left[R_{t, t+1}\right]$} \\
\cline { 2 - 4 }$\gamma / \boldsymbol{\rho}$ & 0.5 & 1 & 1.5 \\
\hline 2 & 0.69 & 0.63 & 0.57 \\
5 & 1.82 & 1.76 & 1.7 \\
10 & 3.71 & 3.65 & 3.59 \\
20 & 7.49 & 7.43 & 7.36 \\
\hline
\end{tabular}

Note: Risk prices are multiplied by 100 .

\section{Conclusion}

Post hiper-inflation Brazilian data on aggregate consumption and stock excess returns challenge the CCAPM model demanding alternative explanations for risk. In this paper, we adopt the long run risks model proposed by Hansen et al. (2008) where a combination of consumption predictability with a recursive utility that is sensitive to the future path of consumption introduces a new channel of risk not captured by a traditional power utility. We carefully analyze the time series of Brazilian consumption and GDP ending up identifying, via a VAR model with transitory and permanent shocks, the dynamics of consumption uncertainty and its role on the proposed long run risks model. We identify that the Epstein-Zin utility function generates an important component of equity risk premia not captured by the Power utility. As a possible topic for future research, a more general long run risks model with stochastic volatility could be calibrated to be compared with the current model aiming at targeting the high variation of the volatility of equity returns in Brazil, with the expense of having less analytical tractability.

\section{References}

Aguiar, M., \& Gopinath, G. (2007). Emerging market business cycles: The cycle is the trend. Journal of Political Economy, 115(1), 69-102. http:// dx.doi.org/10.1086/511283

Bansal, R., Dittmar, R., \& Kiku, D. (2007). Cointegration and consumption risks in asset returns. The Review of Financial Studies, 22(3), 1343-1375. http://dx.doi.org/10.1093/rfs/hhm085

Bansal, R., \& Kiku, D. (2011). Cointegration and long-run asset allocation. Journal of Business \&6 Economic Statistics, 29(1), 161-173. http:// dx.doi.org/10.1198/jbes.2010.08062 
Bansal, R., Kiku, D., \& Yaron, A. (2012). An empirical evaluation of the longrun risks model for asset prices. Critical Finance Review, 1(1), 183-221. http://dx.doi.org/10.1561/104.00000005

Bansal, R., \& Shaliastovich, I. (2012). A long-run risks explanation of predictability puzzles in bond and currency markets. The Review of Financial Studies, 26(1), 1-33. http://dx.doi.org/10.1093/rfs/hhs108

Bansal, R., \& Yaron, A. (2004). Risks for the long run: A potential resolution of asset pricing puzzles. The Journal of Finance, 59(4), 1481-1509. http:// dx.doi.org/10.1111/j.1540-6261.2004.00670.x

Beeler, J., \& Campbell, J. Y. (2012). Appendix for "the long-run risks model and aggregate asset prices: An empirical assessment". Critical Finance Review.

Beveridge, S., \& Nelson, C. R. (1981). A new approach to the decomposition of economic time series into permanent and transitory components with particular attention to the measurement of the 'business cycle'. Journal of Monetary Economics, 7(2), 151-174. http://dx.doi.org/10.1016/ 0304-3932(81)90040-4

Blanchard, O. J., \& Quah, D. (1989). The dynamic effects of aggregate demand and supply disturbances. The American Economic Review, 79(4), 655-673. https://www.jstor.org/stable/1827924

Bonomo, M. (Ed.). (2004). Finanças aplicadas ao Brasil. Editora FGV.

Bonomo, M., \& Domingues, G. B. (2002). Os puzzles invertidos no mercado brasileiro de ativos. In M. Bonomo (Ed.), Finanças aplicadas ao Brasil (pp. 105-120). Rio de Janeiro: Editora FGV.

Campbell, J. Y. (1987). Does saving anticipate declining labor income? An alternative test of the permanent income hypothesis. Econometrica, 55(6), 1249-1273. http://dx.doi.org/10.2307/1913556

Campbell, J. Y. (2003). Consumption-based asset pricing. In G. M. Constantinides, M. Harris, \& R. M. Stulz (Eds.), Handbook of the economics of finance (Vols. 1, Part B, pp. 803-887). Amsterdam: North-Holland. http://dx.doi.org/10.1016/S1574-0102(03)01022-7

Campbell, J. Y., \& Vuolteenaho, T. (2004). Bad beta, good beta. The American Economic Review, 94(5), 1249-1275. https://www.jstor.org/ stable/3592822

Cochrane, J. H. (1994). Permanent and transitory components of GNP and stock prices. The Quarterly Journal of Economics, 109(1), 241-265. http://dx.doi.org/10.2307/2118434

Colacito, R., \& Croce, M. M. (2011). Risks for the long run and the real exchange rate. Journal of Political Economy, 119(1), 153-181. http:// dx.doi.org/10.1086/659238

Cysne, R. P. (2006). Equity-premium puzzle: Evidence from Brazilian data. Economia Aplicada, 10(2), 161-180. http://dx.doi.org/10.1590/S1413 $-80502006000200001$ 
Da, Z. (2009). Cash flow, consumption risk, and the cross-section of stock returns. The Journal of Finance, 64(2), 923-956. http://dx.doi.org/ 10.1111/j.1540-6261.2009.01453.x

Epstein, L., \& Zin, S. E. (1989). Substitution, risk aversion and the temporal behavior of consumption and asset returns: A theoretical framework. Econometrica, 57(6), 937-969. http://dx.doi.org/10.2307/1913778

Hansen, L. P., Heaton, J., Lee, J., \& Roussanov, N. (2007). Intertemporal substitution and risk aversion. In J. J. Heckman \& E. E. Leamer (Eds.), Handbook of econometrics (Vols. 6, Part A, pp. 3967-4056). North-Holland. http://dx.doi.org/10.1016/S1573-4412(07)06061-8

Hansen, L. P., Heaton, J. C., \& Li, N. (2008). Consumption strikes back? Measuring long-run risk. Journal of Political Economy, 116(2), 260-302. http://dx.doi.org/10.1086/588200

Hansen, L. P., \& Singleton, K. J. (1982). Generalized instrumental variables estimation of nonlinear rational expectations models. Econometrica, 50(5), 1269-1286. http://dx.doi.org/10.2307/1911873

Issler, J. V., \& Piqueira, N. S. (2000). Estimating relative risk aversion, the discount rate, and the intertemporal elasticity of substitution in consumption for Brazil using three types of utility function. Brazilian Review of Econometrics, 20(2), 201-239. http://dx.doi.org/10.12660/ bre.v20n22000.2758

Johansen, S. (1991). Estimation and hypothesis testing of cointegration vectors in Gaussian vector autoregressive models. Econometrica, 59(6), 1551-1580. http://dx.doi.org/10.2307/2938278

Lettau, M., \& Wachter, J. A. (2007). Why is long-horizon equity less risky? A duration-based explanation of the value premium. The Journal of Finance, 62(1), 55-92. http://dx.doi.org/10.1111/j.1540-6261.2007.01201.x

Mehra, R., \& Prescott, E. C. (1985). The equity premium: A puzzle. Journal of monetary Economics, 15(2), 145-161. http://dx.doi.org/10.1016/ 0304-3932(85)90061-3

Parker, J. A., \& Julliard, C. (2005). Consumption risk and the cross section of expected returns. Journal of Political Economy, 113(1), 185-222. http://dx.doi.org/10.1086/426042

Reis, R. (2009). The time-series properties of aggregate consumption: Implications for the costs of fluctuations. Journal of the European Economic Association, 7(4), 722-753. http://dx.doi.org/10.1162/JEEA.2009.7.4.722

Sampaio, F. S. (2002). Existe equity premium puzzle no Brasil. In M. Bonomo (Ed.), Finanças aplicadas ao Brasil (Vol. 1, pp. 87-117). Rio de Janeiro: Editora FGV.

Soriano, A. (2002). Testando o CCAPM através das fronteiras de volatilidade e da equação de Euler. In M. Bonomo (Ed.), Finanças aplicadas ao Brasil (pp. 8-25). Rio de Janeiro: Editora FGV. 
Van Binsbergen, J., Brandt, M., \& Koijen, R. (2012). On the timing and pricing of dividends. American Economic Review, 102(4), 1596-1618. http://dx.doi.org/10.1257/aer.102.4.1596

\section{Appendix A}

\section{A.1 Stochastic Discount Factor}

In this appendix, we provide formulas for the stochastic discount factor approximation. We first compute the coefficients for the derivative of the value function for $\rho=1$ :

$$
D v_{t}^{1}=-\frac{(1-\beta)}{2 \beta}\left(v_{t}^{1}\right)^{2}+\beta \mathbb{E}_{t}^{*}\left[D v_{t+1}^{1}\right]
$$

Write $\left(v_{t}^{1}\right)^{2}$ as

$$
\left(v_{t}^{1}\right)^{2}=A_{0}+2 x_{t}^{\prime} A_{1}+x_{t}^{\prime} A_{2} x_{t},
$$

where the coefficients $\left(A_{0}, A_{1}, A_{2}\right)$ are obtained using the solution $v_{t}^{1}=\mu_{v}+U_{v} x_{t}$ :

$$
\begin{aligned}
& A_{0}=\mu_{v}^{2}, \\
& A_{1}=\mu_{v} U_{v}, \\
& A_{2}=U_{v}^{\prime} U_{v} .
\end{aligned}
$$

It can be verified that equation (80) has the linear quadratic solution

$$
D v_{t}^{1}=-\frac{1}{2} x_{t}^{\prime} B_{2} x_{t}-B_{1} x_{t}-\frac{B_{0}}{2}
$$

where

$$
\begin{aligned}
B_{0}= & \frac{1-\beta}{\beta} A_{0}+\beta B_{0}+\beta \operatorname{tr}\left(H^{\prime} B_{2} H\right) \\
+ & \beta(1-\gamma)^{2}\left[\lambda_{c}+\beta U_{c}(I-\beta G)^{-1} H\right] H^{\prime} B_{2} H\left[\lambda_{c}+\beta U_{c}(I-\beta G)^{-1} H\right] \\
& +2 \beta(1-\gamma) B_{1} H\left[\lambda_{c}+\beta U_{c}(I-\beta G)^{-1} H\right], \\
B_{1}= & \frac{1-\beta}{\beta} A_{1}+\beta B_{1} G+\beta(1-\gamma)\left[\lambda_{c}+\beta U_{c}(I-\beta G)^{-1} H\right]^{\prime} H^{\prime} B_{2} G, \\
B_{2}= & \frac{1-\beta}{\beta} A_{2}+\beta G^{\prime} B_{2} G .
\end{aligned}
$$

To obtain the approximation for the stochastic discount factor, take the derivative of $s_{t, t+1}^{\rho}$ with respect to $\rho$ and write

$$
\begin{aligned}
D s_{t+1}^{\rho}=v_{t+1}^{\rho}-\log \mathcal{R}_{t}\left(\exp \left\{v_{t+1}+\Delta c_{t+1}\right\}\right) & \\
& +(\rho-\gamma)\left(D v_{t+1}^{\rho}-\mathbb{E}_{t}^{*}\left[D v_{t+1}^{\rho}\right]\right),
\end{aligned}
$$


where the expectation $\mathbb{E}_{t}^{*}[\cdot]$ is taken with respect to the probability distorted by

$$
\frac{\exp \left\{(1-\gamma)\left(v_{t+1}^{1}+\Delta c_{t+1}\right)\right\}}{\mathbb{E}_{t}\left[\exp \left\{(1-\gamma)\left(v_{t+1}^{1}+\Delta c_{t+1}\right)\right\}\right]} .
$$

Under the distorted probability measure, shocks are distributed as

$$
\mathcal{N}\left((1-\gamma)\left(\lambda_{c}+U_{v} H, I\right)\right)
$$

Write the solution for the derivative of the stochastic discount factor as

$$
D s_{t+1}^{1}=C_{0}+C_{1} x_{t}+C_{2} \varepsilon_{t+1}+x_{t}^{\prime} C_{3} \varepsilon_{t+1}+\varepsilon_{t+1}^{\prime} C_{4} \varepsilon_{t+1},
$$

where

$$
\begin{aligned}
& C_{0}=- \mu_{c}-\frac{(1-\gamma)}{2}\left[\operatorname{tr}\left(H^{\prime} B_{1} H\right)-\left|\lambda_{c}+U_{v} H\right|^{2}+(1-\gamma) B_{1} H \lambda_{c}\right. \\
&\left.\quad+U_{v} H+(1-\gamma)^{2}\left(\lambda_{c}+U_{v} H\right)^{\prime} H^{\prime} B_{2} H\left(\lambda_{c}+U_{v} H\right)\right], \\
& C_{1}=-U_{c}+(1-\gamma)^{2}\left(\lambda_{c}+U_{v} H\right)^{\prime} H^{\prime} B_{2} G \\
& C_{2}=U_{v} H-(1-\gamma) B_{1} H \\
& C_{3}-(1-\gamma) G^{\prime} B_{2} H \\
& C_{4}=-\frac{(1-\gamma)}{2} H^{\prime} B_{2} H .
\end{aligned}
$$

The stochastic discount factor is then approximated by the equation

$$
\begin{aligned}
s_{\rho}^{t+1} & =s_{t+1}^{1}+(\rho-1) D s_{t+1}^{1} \\
& =D_{0}+D_{1} x_{t}+D_{2} \varepsilon_{t+1}+x_{t}^{\prime} D_{3} \varepsilon_{t+1}+\varepsilon_{t+1}^{\prime} D_{4} .
\end{aligned}
$$

\section{A.2 Pricing equation}

In the general case, we are interested in pricing assets whose stationary components have the form

$$
\phi_{0}+\phi_{1} x_{t+1}+\frac{1}{2} x_{t+1}^{\prime} \phi_{2} x_{t+1} .
$$

Applying the operator $\mathcal{P}(\cdot)$ to the above equation and using the approximate stochastic discount factor, we find that

$$
\begin{aligned}
\mathcal{P}\left(\phi_{0}+\phi_{1} x_{t+1}+\frac{1}{2} x_{t+1}^{\prime} \phi_{2} x_{t+1}\right) & \\
& =\exp \left\{\phi_{0}^{*}+\phi_{1}^{*} x_{t+1}+\frac{1}{2} x_{t+1}^{\prime} \phi_{2}^{*} x_{t+1}\right\},
\end{aligned}
$$


where

$$
\begin{aligned}
\phi_{0}^{*}= & \phi_{0}-\mu_{s}-\mu_{d}+\log \left(\left|I-D_{4}+H^{\prime} \phi_{2} H\right|^{1 / 2}\right) \\
& \quad-\frac{1}{2}\left(\lambda_{s}+\pi_{d}-\phi_{1} H\right)^{\prime}\left(I-D_{4}+H^{\prime} \phi_{2} H\right)^{-1}\left(\lambda_{s}+\pi_{d}-\phi_{1} H\right), \\
\phi_{1}^{*}=-U_{s}+\phi_{1} G & \quad-\left(\lambda_{s}+\pi_{d}-\phi_{1} H\right)^{\prime}\left(I-D_{4}+H^{\prime} \phi_{2} H\right)^{-1}\left(D_{3}-H^{\prime} \phi_{2} G\right), \\
\phi_{2}^{*}= & G^{\prime} \phi_{2} G-\left(D_{3}-H^{\prime} \phi_{2} G\right)^{\prime}\left(I-D_{4}+H^{\prime} \phi_{2} H\right)^{-1}\left(D_{3}-H^{\prime} \phi_{2} G\right) .
\end{aligned}
$$

We find the eigenvalue and the eigenfunction of the operator $\mathcal{P}(\cdot)$ by solving the equation:

$$
\mathcal{P}\left(\bar{\phi}_{1} x_{t+1}+\frac{1}{2} x_{t+1}^{\prime} \bar{\phi}_{2} x_{t+1}\right)=e^{-\nu} \exp \left\{\bar{\phi}_{1} x_{t+1}+\frac{1}{2} x_{t+1}^{\prime} \bar{\phi}_{2} x_{t+1}\right\} .
$$

The eigenfunction is defined by $\left(\bar{\phi}_{1}, \bar{\phi}_{2}\right)$, where:

$$
\begin{aligned}
\bar{\phi}_{1}=- & \left(U_{s}+\left(\lambda_{s}+\pi_{d}\right)\left(I-D_{4}+H^{\prime} \bar{\phi}_{2} H\right)^{-1}\left(D_{3}-H^{\prime} \bar{\phi}_{2} G\right)\right) \\
& \times\left(I-G-H\left(I-D_{4}+H^{\prime} \bar{\phi}_{2} H\right)^{-1}\left(D_{3}-H^{\prime} \bar{\phi}_{2} G\right)^{\prime}\right) \\
\bar{\phi}_{2}= & G^{\prime} \bar{\phi}_{2} G-\left(D_{3}-H^{\prime} \bar{\phi}_{2} G\right)^{\prime}\left(I-D_{4}+H^{\prime} \bar{\phi}_{2} H\right)^{-1}\left(D_{3}-H^{\prime} \bar{\phi}_{2} G\right) .
\end{aligned}
$$

and the eigenvalue is given by

$$
\begin{aligned}
\nu=-\mu_{s} & -\mu_{d}-\log \left(\left|I-D_{4}+H^{\prime} \bar{\phi}_{2} H\right|^{1 / 2}\right) \\
& -\frac{1}{2}\left(\lambda_{s}+\pi_{d}-\bar{\phi}_{1} H\right)^{\prime}\left(I-D_{4}+H^{\prime} \bar{\phi}_{2} H\right)^{-1}\left(\lambda_{s}+\bar{\pi}_{d}-\bar{\phi}_{1} H\right) .
\end{aligned}
$$

